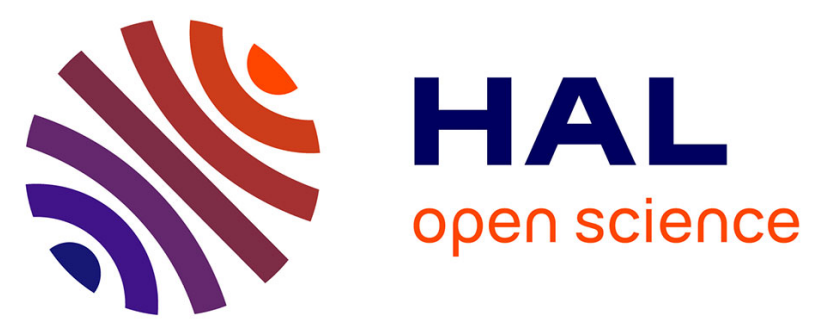

\title{
Joint Inversion of Coseismic and Early Postseismic Slip to Optimize the Information Content in Geodetic Data: Application to the 2009 M w 6.3 L'Aquila Earthquake, Central Italy
}

Théa Ragon, Anthony Sladen, Quentin Bletery, Mathilde Vergnolle, Olivier Cavalié, Antonio Avallone, Julien Balestra, Bertrand Delouis

\section{To cite this version:}

Théa Ragon, Anthony Sladen, Quentin Bletery, Mathilde Vergnolle, Olivier Cavalié, et al.. Joint Inversion of Coseismic and Early Postseismic Slip to Optimize the Information Content in Geodetic Data: Application to the 2009 M w 6.3 L'Aquila Earthquake, Central Italy. Journal of Geophysical Research : Solid Earth, 2019, 124 (10), pp.10522-10543. 10.1029/2018JB017053 . hal-02383105v2

\section{HAL Id: hal-02383105 \\ https://hal.science/hal-02383105v2}

Submitted on 3 Feb 2022

HAL is a multi-disciplinary open access archive for the deposit and dissemination of scientific research documents, whether they are published or not. The documents may come from teaching and research institutions in France or abroad, or from public or private research centers.
L'archive ouverte pluridisciplinaire HAL, est destinée au dépôt et à la diffusion de documents scientifiques de niveau recherche, publiés ou non, émanant des établissements d'enseignement et de recherche français ou étrangers, des laboratoires publics ou privés. 


\author{
RESEARCH ARTICLE \\ 10.1029/2018JB017053 \\ Key Points: \\ - Simultaneous inversion of geodetic \\ data with different spatiotemporal \\ resolution maximizes the \\ information content \\ - If the early afterslip signal is \\ neglected, coseismic slip is \\ overestimated by $30 \%$ and \\ postseismic slip is underestimated by \\ a factor of 3 \\ - Early afterslip (6 days after \\ mainshock) is mainly located at the \\ transition zone between coseismic \\ rupture and longer-term afterslip
}

Supporting Information:

- Supporting Information S1

Correspondence to:

T. Ragon,

tragon@caltech.edu

\section{Citation:}

Ragon, T., Sladen, A., Bletery, Q.,

Vergnolle, M., Cavalié, O., Avallone, A., et al. (2019). Joint inversion of coseismic and early postseismic slip to optimize the information content in geodetic data: Application to the $2009 M_{w} 6.3$ L'Aquila earthquake, Central Italy. Journal of Geophysical Research: Solid Earth, 124, 10,522-10,543. https://doi. org/10.1029/2018JB017053

Received 20 NOV 2018 Accepted 3 SEP 2019

Accepted article online 8 SEP 2019 Published online 30 OCT 2019 (c)2019. American Geophysical Union. All Rights Reserved.
Joint Inversion of Coseismic and Early Postseismic Slip to Optimize the Information Content in Geodetic Data: Application to the $2009 M_{w} 6.3$ L'Aquila Earthquake, Central Italy

\author{
Théa Ragon $^{1,2}$ (D), Anthony Sladen ${ }^{1}$ (D), Quentin Bletery ${ }^{1}$ iD, Mathilde Vergnolle ${ }^{1}$ (D), \\ Olivier Cavalié ${ }^{1}$, Antonio Avallone ${ }^{3}$ (iD, Julien Balestra ${ }^{1}$, and Bertrand Delouis ${ }^{1}$ (iD) \\ ${ }^{1}$ Université Côte d'Azur, CNRS, IRD, Observatoire de la Côte d'Azur, Géoazur, Valbonne, France, ${ }^{2}$ Now at Seismological \\ Laboratory, California Institute of Technology, Pasadena, CA, USA, ${ }^{3}$ Istituto Nazionale di Geofisica e Vulcanologia, Rome, \\ Italy
}

\begin{abstract}
When analyzing the rupture of a large earthquake, geodetic data are often critical. These data are generally characterized by either a good temporal or a good spatial resolution, but rarely both. As a consequence, many studies analyze the coseismic rupture with data that also include one or more days of early postseismic deformation. Here, we invert simultaneously for the coseismic and postseismic slip with the condition that the sum of the two models remains compatible with data covering the two slip episodes. We validate the benefits of this approach with a toy model and an application to the $2009 M_{w} 6.3$ L'Aquila earthquake, using a Bayesian approach and accounting for epistemic uncertainties. For the L'Aquila earthquake, we find that if early postseismic deformation is not an explicitly acknowledged coseismic signal, coseismic slip models may overestimate the peak amplitude while long-term postseismic models may largely underestimate the total postseismic slip amplitude. This example illustrates how the proposed approach could improve our comprehension of the seismic cycle, fault frictional properties, and the spatial and temporal relationship between seismic rupture, afterslip, and aftershocks.
\end{abstract}

\section{Introduction}

The occurrence of earthquakes and seismic sequences is mainly controlled by the spatial and temporal evolution of crustal stresses. The coseismic stress changes and the redistribution of stress following an earthquake thus both play an important role in the seismic cyle and the mechanical behavior of faults, including the generation of new seismic sequences. To understand both coseismic and postseismic processes, and their relationship, is thus a crucial step to propose realistic earthquake scenarios and reliable hazard estimates.

While earthquakes can last for a few seconds to minutes, the subsequent period of postseismic stress relaxation can last months to years. Postseismic relaxation is generally modeled by several interacting mechanisms, such as localized shear on the fault (also known as afterslip; e.g., Freed, 2007; Johnson et al., 2012; Marone et al., 1991), viscoelastic deformation in the lower crust or mantle (e.g., Freed \& Burgmann, 2004; Nur \& Mavko, 1974; Pollitz et al., 1998), or poroelastic rebound (e.g., Jonsson et al., 2003; Peltzer et al., 1998). The interactions between coseismic stress changes, aftershocks, and postseismic deformation are still poorly understood (e.g., Perfettini \& Avouac, 2007). Slip on the fault may be governed by two brittle deformation modes following rate and state friction laws (Rice \& Ruina, 1983): Seismic rupture may occur in velocity weakening areas, whereas afterslip may develop in velocity strengthening zones (e.g., Marone et al., 1991). In contrast, Helmstetter and Shaw (2009) also show that afterslip processes may be primarily driven by stress heterogeneities, independently of the rate and state friction behavior. Aftershocks may be triggered by coseismic stress changes, without direct relation to postseismic deformation (Dieterich, 1994). Or aftershocks may also be primarily triggered by the postseismic reloading due to afterslip (e.g., Hsu et al., 2006; Peng \& Zhao, 2009; Perfettini \& Avouac, 2004; Ross et al., 2017). The variability of these theories emphasizes the need to refine our comprehension and description of the coseismic and postseismic phases and their transition. 
Our understanding of the coseismic processes mainly derives from modeling of seismic, geodetic, and tsunami data, and our understanding of postseismic behavior is mainly based on the modeling of geodetic observations (e.g., Burgmann et al., 1997; Gualandi et al., 2017; Perfettini \& Avouac, 2014; Wang et al., 2012) or simulation (e.g., Barbot \& Fialko, 2010; Cubas et al., 2015; Smith \& Sandwell, 2004). Geodetic observations thus remain a cornerstone to identify and characterize the coseismic and postseismic processes. Global Navigation Satellite Systems (GNSS) time series are commonly used and can provide a good temporal resolution (seconds to days). But the spatial resolution of such observations is usually limited, as GNSS stations are usually several tens or hundreds of kilometers apart. In contrast, synthetic aperture radar interferometry (InSAR) can provide extensive spatial coverage (in the order of a meter) but with a limited temporal resolution. Indeed, while earthquakes last for a few seconds, very often satellites have a revisit time of more than a few days. If earthquakes do not nucleate just before the visit of a satellite, which is generally the case, the measured deformation is the coseismic signal plus a fraction of the postseismic deformation. As a consequence, most earthquake models based on geodetic observations are biased by an unwanted postseismic deformation signal. In practice, both coseismic interferograms or campaign GNSS offsets generally cover time periods extending at least a few days before and after the mainshock. Pre-earthquake signals, when evidenced, are usually related to small slip episodes at depth near the hypocenter (e.g., Kato et al., 2012; Ruiz et al., 2014). The associated surface deformation signals are usually hard to detect and are neglected in coseismic studies. The postseismic deformation happening in the first few days after the mainshock is usually detectable in the geodetic data but incorporated in source estimation problems as if it was part of the coseismic signal (e.g., Barnhart et al., 2018; Bletery et al., 2016; Cheloni et al., 2014; Elliott et al., 2013; He et al., 2017; Lin et al., 2013; Salman et al., 2017), with the justification that it is comparatively small. Similarly, postseismic models generally do not account for observations related to the early postseismic deformation because they are often contaminated by coseismic signal (e.g., Cheloni et al., 2014; D'Agostino et al., 2012). What we name here the early postseismic phase corresponds to the overlooked part of the postseismic deformation and can last from a few hours after the mainshock in the best case to a few days in most studies. Yet, the largest postseismic deformation rate is expected during the first few days after the mainshock, considering that its main trend is to decrease exponentially with time after an earthquake.

This early postseismic phase remains largely unexplored, because of the limited temporal and spatial resolution of geodetic data (e.g., Twardzik et al., 2019). Neglecting this phase may also bias our understanding of both coseismic and postseismic processes. And this bias is probably persisting if seismic data (i.e., purely coseismic) are added to the inverse problem, since geodetic data tend to have a stronger control on the inferred distribution of slip, at least in the first $10 \mathrm{~km}$ below the Earth surface (e.g., Delouis et al., 2002).

The recent advent of high-frequency GNSS has allowed the recording of the strictly coseismic signal (10 to $30 \mathrm{~s}$ after the earthquake time occurrence) without any contamination by early postseismic deformation (e.g., Twardzik et al., 2019). Well-instrumented earthquakes are thus now characterized by at least two geodetic data sets, one being strictly coseismic and the other including some days of early afterslip. In this study, we propose a generic inversion methodology to jointly infer coseismic and early postseismic slip models, taking advantage of the complementary spatial and temporal resolutions of different geodetic observations (typically InSAR and image correlation data). A comparable approach has been employed by Floyd et al. (2016) and Walters et al. (2018). To further explore the potential of the approach, we first explicitly detail the governing equations of the implementation and then evaluate the approach through a toy model. We also analyze and illustrate the benefits of the methodology with a real event, our analyses being performed in a Bayesian framework. In detail, we investigate the impact of accounting for early afterslip on coseismic models. We consider the $2009 M_{w} 6.3$ L'Aquila earthquake, Central Italy, which has been intensively studied but whose very early postseismic phase has not been imaged. The choice of the L'Aquila event is also motivated by the large density of near-field observations and the overall quality of the instrumentation. Additionally, this event ruptured a relatively well-known and simple fault geometry, in an area where crustal properties have been investigated in detail: This will ensure the forward physics, and its uncertainties can be estimated.

\section{Inversion Framework}

\subsection{Dual Time Inversion of Coseismic and Early Postseismic Data}

For a number of earthquakes, we have the opportunity to use two static data sets: one which is strictly coseismic ("co") and the other which contains coseismic and early postseismic signal ("co+post"). To infer the 
strictly coseismic and early postseismic slip distributions, one approach could be to invert separately for the two data sets and assume that the strictly postseismic ("post") solution is the difference between the co and co+post models. However, in this case, the model co would be constrained by fewer observations (only few GNSS offsets), most of the coseismic information being in the co+post data set (dense map of InSAR offsets). An alternative approach is to assume that the co+post slip model is the sum of the co and post slip distributions (e.g., Floyd et al., 2016; Walters et al., 2018). We then have

$$
\left\{\begin{array}{l}
\mathbf{d}_{\mathrm{co}}=\mathbf{G}_{\mathrm{co}}^{\mathrm{co}} \cdot \mathbf{m}_{\mathrm{co}} \\
\mathbf{d}_{\mathrm{co}+\text { post }}=\mathbf{G}_{\mathrm{co}+\text { post }}^{\mathrm{co}} \cdot \mathbf{m}_{\mathrm{co}}+\mathbf{G}_{\mathrm{co}+\text { post }}^{\mathrm{post}} \cdot \mathbf{m}_{\mathrm{post}}
\end{array}\right.
$$

where matrices of the Green's functions $\mathbf{G}_{\mathrm{data}}^{\text {model }}$ have been calculated for the corresponding data set and model. For instance, $\mathbf{G}_{\mathrm{co}+\text { post }}^{\mathrm{co}}$ is the matrix of the Green's functions calculated from the model co for the data co+post. Equation (1) can also be represented in the following matrix form:

$$
\left(\begin{array}{c}
\mathbf{d}_{\mathrm{co}} \\
\mathbf{d}_{\mathrm{co}+\text { post }}
\end{array}\right)=\left(\begin{array}{cc}
\mathbf{G}_{\mathrm{co}}^{\mathrm{co}} & 0 \\
\mathbf{G}_{\mathrm{co}+\text { post }}^{\mathrm{co}} & \mathbf{G}_{\mathrm{co}+\text { post }}^{\text {post }}
\end{array}\right) \cdot\left(\begin{array}{c}
\mathbf{m}_{\mathrm{co}} \\
\mathbf{m}_{\text {post }}
\end{array}\right)
$$

The redesigned Green's functions matrix is now composed of three submatrices. As we focus on the early postseismic phase, we can make the assumption that both $\mathbf{G}_{\mathrm{co}+\text { post }}^{\mathrm{co}}$ and $\mathbf{G}_{\mathrm{co}+\text { post }}^{\text {post }}$ matrices are identical because we suppose both coseismic and early postseismic deformations are elastic. We can thus write

$$
\left(\begin{array}{c}
\mathbf{d}_{\mathrm{co}} \\
\mathbf{d}_{\mathrm{co}+\mathrm{post}}
\end{array}\right)=\left(\begin{array}{cc}
\mathbf{G}_{\mathrm{co}} & 0 \\
\mathbf{G}_{\mathrm{co}+\mathrm{post}} & \mathbf{G}_{\mathrm{co}+\mathrm{post}}
\end{array}\right) \cdot\left(\begin{array}{c}
\mathbf{m}_{\mathrm{co}} \\
\mathbf{m}_{\mathrm{post}}
\end{array}\right) .
$$

If strictly postseismic observations are available, we could also incorporate these data into our equation to help constrain the post model:

$$
\left(\begin{array}{c}
\mathbf{d}_{\mathrm{co}} \\
\mathbf{d}_{\mathrm{co}+\text { post }} \\
\mathbf{d}_{\mathrm{post}}
\end{array}\right)=\left(\begin{array}{cc}
\mathbf{G}_{\mathrm{co}}^{\mathrm{co}} & 0 \\
\mathbf{G}_{\mathrm{co}+\text { post }}^{\mathrm{co}} & \mathbf{G}_{\mathrm{co}+\text { post }}^{\text {post }} \\
0 & \mathbf{G}_{\mathrm{post}}^{\text {post }}
\end{array}\right) \cdot\left(\begin{array}{c}
\mathbf{m}_{\mathrm{co}} \\
\mathbf{m}_{\mathrm{post}}
\end{array}\right),
$$

with $\mathbf{G}_{\text {post }}^{\text {post }}$ reflecting the response of the Earth for the strictly postseismic data. The post data set then corresponds to the same postseismic time window as that covered by the co+post data set.

The off-diagonal terms of the redesigned Green's function matrix allow us to make use of the co+post data set to constrain both co and post models. In the following, we refer to this approach as Combined Time Windows (CTW) approach. The CTW approach can be generalized to cover various intervals of postseismic deformation. Indeed, while for many earthquakes strictly coseismic data are now available, nonstrictly coseismic data sets usually cover variable time intervals. If, for instance, two intervals of postseismic deformation contaminate the coseismic signal, with only one of these intervals observed independently, our equation (3) can be adapted as

$$
\left(\begin{array}{c}
\mathbf{d}_{\mathrm{co}} \\
\mathbf{d}_{\mathrm{co}+\text { post1 }} \\
\mathbf{d}_{\mathrm{co}+\text { post2 }} \\
\mathbf{d}_{\mathrm{pos} 22}
\end{array}\right)=\left(\begin{array}{ccc}
\mathbf{G}_{\mathrm{co}}^{\mathrm{co}} & 0 & 0 \\
\mathbf{G}_{\mathrm{co}+\text { post1 }}^{\mathrm{co}} & \mathbf{G}_{\mathrm{co}+\text { post1 }}^{\mathrm{post1}} & 0 \\
\mathbf{G}_{\mathrm{co}+\text { post2 } 2}^{\mathrm{co}} & \mathbf{G}_{\mathrm{co}+\text { post2 } 2}^{\text {post }} & \mathbf{G}_{\mathrm{co}+\text { post2 }}^{\text {post }} \\
0 & 0 & \mathbf{G}_{\mathrm{post2}}^{\text {post }}
\end{array}\right) \cdot\left(\begin{array}{c}
\mathbf{m} \mathrm{co} \\
\mathbf{m}_{\text {post1 }} \\
\mathbf{m}_{\text {post2 }}
\end{array}\right),
$$

with $\mathbf{d}_{\text {post2 }}$ reflecting the surface displacement for the time interval between times 1 and 2 , and $\mathbf{G}_{\text {post2 } 2}^{\text {post and }}$ $\mathbf{m}_{\text {post2 }}$ associated Green's functions and slip model. Indeed, this approach could be used to investigate as many time windows of postseismic deformation as needed.

To refine coseismic models and investigate early postseismic deformation of the L'Aquila earthquake, we follow here the approach described by equations (1) and (3). We do not incorporate any information on 
the strictly postseismic phase to investigate the very simple case where only coseismic data (contaminated or not by early postseismic deformation) are available.

\subsection{Accounting for Epistemic Uncertainties}

When imaging a slip distribution on a fault, the physics of the forward model is usually assumed of minimum complexity to simplify the computation and also often because we do not know well the Earth's interior rheological structure. For instance, this structure is frequently approximated as a homogenous elastic halfspace and the causative fault geometry is usually reduced to a flat rectangular plane. The uncertainties related to our approximations of the physics of the Earth affect the inferred source models (Ragon et al., 2018). As the early postseismic slip is of limited amplitude, it may be particularly impacted by uncertainties of the forward model. We thus account for epistemic uncertainties following the approach developed by Duputel et al. (2014) for the Earth elastic properties and Ragon et al. (2018) for the fault geometry. The epistemic uncertainties are calculated from the sensitivity of the Green's functions and are included in a covariance matrix $\mathbf{C}_{\mathrm{p}}$.

\subsection{Bayesian Approach}

Our inverse problem solves for both coseismic and early postseismic slip parameters, the latter being of limited amplitude. While the coseismic parameters will be reasonably well constrained, multiple and probably different early postseismic models will probably be equally realistic, as they will equally explain the observations. To get a robust image of the early postseismic phase, we thus solve our problem with a Bayesian sampling approach which relies on the AlTar package https:/github.com/AlTarFramework/altar, which is a rewrite of the code CATMIP (Minson et al., 2013). AlTar combines the Metropolis algorithm with a tempering process to realize an iterative sampling of the solution space of the source models. A large number of samples are tested in parallel at each transitional step. Additionally, a resampling is performed at the end of each step to replace less probable models. The probability of each sample to be selected depends on its ability to fit the observations $\mathbf{d}_{\text {obs }}$ within the uncertainties $\mathbf{C}_{\chi}=\mathbf{C}_{\mathrm{d}}+\mathbf{C}_{\mathrm{p}}$, with $\mathbf{C}_{\mathrm{d}}$ the observational errors and $\mathbf{C}_{\mathrm{p}}$ the epistemic uncertainties.

The ability of each model parameter to solve the source problem is evaluated through repeated updates of the probability density functions (PDFs)

$$
f\left(\mathbf{m}, \beta_{i}\right) \propto p(\mathbf{m}) \cdot \exp \left[-\beta_{i} \cdot \chi(\mathbf{m})\right]
$$

where $\mathbf{m}$ is the current sample, $p(\mathbf{m})$ is the prior information on this sample, $i$ corresponds to each iteration, and $\beta$ evolves dynamically from 0 to 1 to ensure an exhaustive exploration of the solution space (Minson et al., 2013). $\chi(\mathbf{m})$ is the misfit function:

$$
\chi(\mathbf{m})=\frac{1}{2}\left[\mathbf{d}_{\mathrm{obs}}-\mathbf{G} \cdot \mathbf{m}\right]^{T} \cdot \mathbf{C}_{\chi}^{-1} \cdot\left[\mathbf{d}_{\mathrm{obs}}-\mathbf{G} \cdot \mathbf{m}\right] .
$$

The use of AlTar with the CTW approach allows us to specify prior information on each model and thus to ensure the quasi-positivity of both coseismic and postseismic slip models (or of any time window model).

The impact of different approaches to regularization, along with the ad hoc choice of smoothing parameters, may bias or induce unwanted artifacts in inferred slip models (e.g., Aster et al., 2005; Beresnev, 2003; Causse et al., 2010; Du et al., 1992; Gallovic et al., 2015; Gombert et al., 2017). Because our Bayesian approach aims at sampling all possible families of models compatible with the observations, it does not include any ad hoc regularization parameter (e.g., Minson et al., 2013).

\section{Application to a Simplified 2-D Model}

To ensure that our methodology allows us to reliably infer the slip distribution of different time windows, we first analyze a synthetic 2-D case where the slip is imaged either independently or with the CTW approach. For this case, we assume two time windows named coseismic and postseismic for simplicity. 


\subsection{Forward Model}

We assume a fault extending infinitely along strike and which is $20 \mathrm{~km}$ wide along dip. The fault is discretized along dip into subfaults of $1-\mathrm{km}$ width and is dipping $55^{\circ}$. We assume the coseismic slip on this fault to be purely dip slip and to vary gradually with depth between 0 and $1.5 \mathrm{~m}$, positive values indicating normal slip, with maximum slip between 9- and 14-km depth. We also assume that there is postseismic slip on the same fault, with a similar location and direction and an amplitude equal to a tenth of the coseismic slip amplitude. We compute the corresponding co and co+post synthetic observations using the expressions of surface displacement in an homogeneous elastic half-space (Segall, 2010). These synthetic observations are computed for a profile line of 100 points, centered on the fault at the surface and spaced every kilometer. The toy model and synthetic data setup are illustrated in supporting information Figure S1. For each data point, the synthetic observations describe the surface displacement along the profile line and the vertical (the along-strike displacement being null). A correlated Gaussian noise of $5 \mathrm{~mm}$ (i.e., noise with a Gaussian amplitude distribution with $5 \mathrm{~mm}$ of standard deviation, characterized by an exponential covariance) is added to the synthetic data to simulate measurement errors. Note that, for this toy model, the number of co data is the same as the number of co+post observations.

Using these 100 synthetic observation points, we then estimate the depth distribution of slip still assuming a homogeneous elastic half-space. We use a uniform prior distribution $p(\mathbf{m})=\mathscr{U}(-1 \mathrm{~m}, 5 \mathrm{~m})$ for the dip-slip component (uniform implies that all values are considered equally likely with no a priori knowledge) and a zero-mean Gaussian prior $p(\mathbf{m})=\mathscr{N}(-0.1 \mathrm{~m}, 0.1 \mathrm{~m})$ on the strike-slip component and include $5 \mathrm{~mm}$ of observational uncertainty in $\mathbf{C}_{\mathrm{d}}$. We do not account for epistemic uncertainties as our forward model is identical to the one used to generate the data. We first solve for the co and post slip following the CTW approach (Figures 1a and 1c). Then, we run independent inversions, one to solve for the co slip (Figure 1b) and the other one to infer the co+post slip. We calculate the postseismic solution as the difference between the co and co+post models (Figure 1d).

\subsection{Results}

Both independent and CTW inversion approaches allow to correctly infer the co slip, as the median of the PDFs is very close to the target model (Figures 1a and 1b). As expected from the inversion of surface data, the resolution is very good on shallow parts of the fault but quickly decreases with depth. The posterior uncertainty on the deepest parameters is slightly decreased in both approaches because the lower tip of the fault acts as an additional constraint. In contrast, the inversion methodology has a larger impact on the inferred post slip distributions. When jointly inverting co and co+post observations, the true post slip is estimated accurately for almost all subfaults (Figure 1c). When solving the two slip stages separately, the mean of the models is not as good at estimating the target model (Figure 1d). The reduced posterior uncertainty of the post model for the independent inversion is an artifact resulting from the subtraction of two Gaussian-shaped curves.

In summary, both of the inversion approaches allow to reliably infer the co slip distributions, probably because its signal is dominating in the observations. But the CTW approach provides a more robust estimation of the post slip distribution. In this 2-D case, coseismic and co+post signals have been observed by the same number of stations. However, for most earthquakes, the number of co data points available (usually GNSS) will be very limited compared to the quantity of co+post observations (usually InSAR). We thus expect that if performing independent inversions for a real event, the inferred co slip distribution will be less reliable than in the case of a CTW inversion, where the whole co+post data set is used to guide the choice of coseismic parameters. We now compare these two approaches on a real earthquake.

\section{Application to the $2009 M_{w} 6.3$ L'Aquila Earthquake, Central Italy}

The L'Aquila earthquake nucleated within the Apennines orogenic system (Figure 2), where the current seismic activity results from the ongoing extensional tectonics of the area. The mainshock nucleated on the Paganica fault (Figure 2; Atzori et al., 2009; Cheloni et al., 2014; Chiaraluce et al., 2011; Falcucci et al., 2009; Lavecchia et al., 2012; Vittori et al., 2011), southwest of the city of L'Aquila, and has been followed by at least four aftershocks of $M_{w}>5$ (Chiarabba et al., 2009; Pondrelli et al., 2010; Scognamiglio et al., 2009). Although the L'Aquila earthquake has been intensively studied, most coseismic and postseismic models have considered the first days of postseismic deformation as if they were part of the coseismic phase 
Coseismic slip marginal PDFs

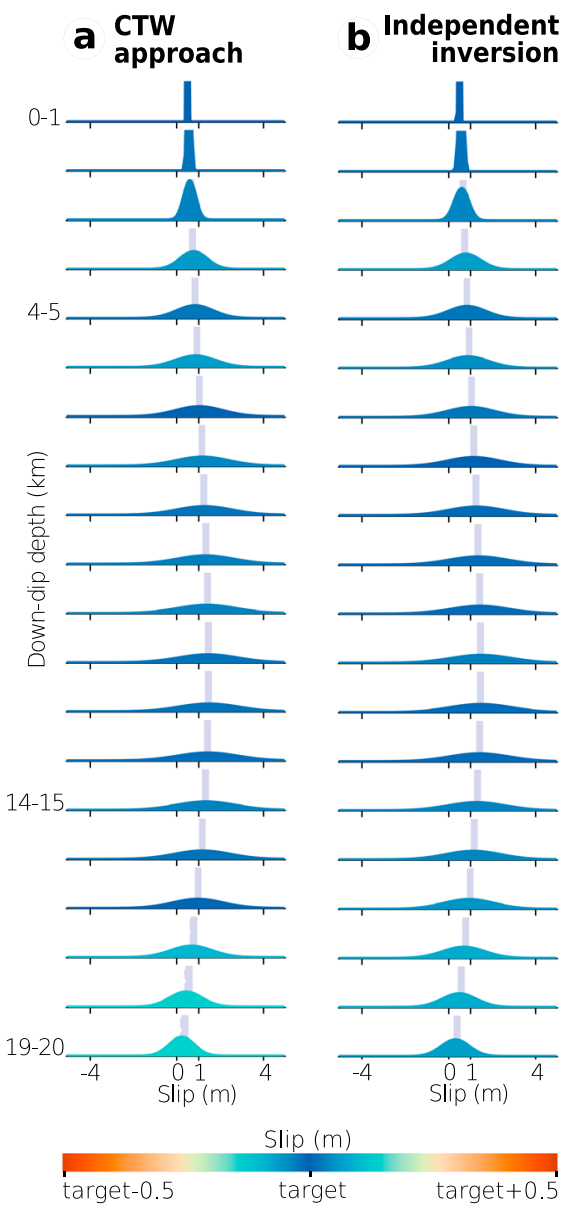

Postseismic slip marginal PDFs

c CTW

approach

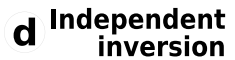
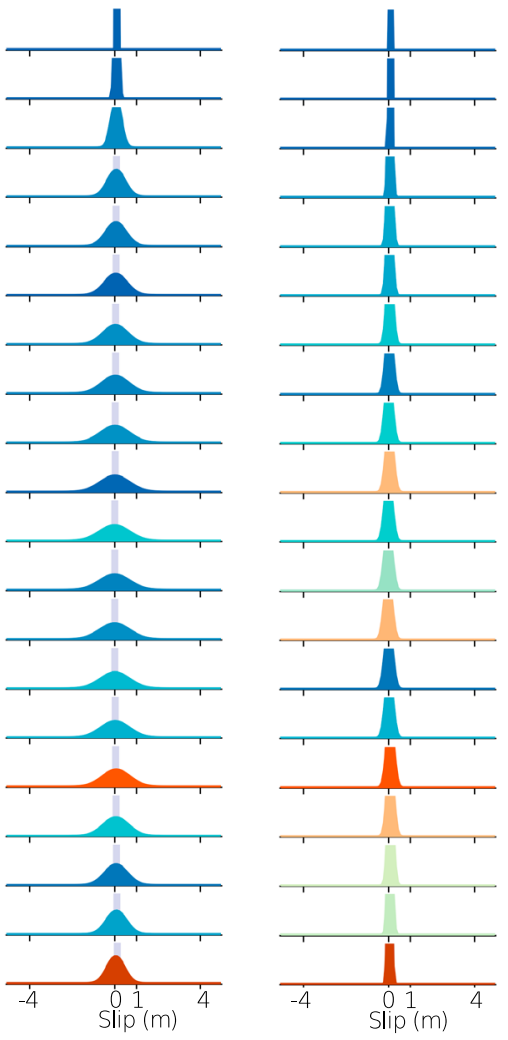

Slip (m)

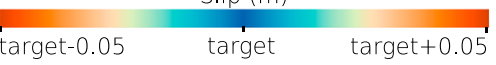

Figure 1. Coseismic and postseismic slip inferred for the simplified case of a fault that extends infinitely along strike. The coseismic and postseismic slip models inferred from the CTW approach are shown in (a) and (c) and can be compared to the slip inferred from the inversion of coseismic data only (b) and the postseismic slip distribution (d) resulting from the difference between slip inferred from the inversion of co+post data and slip of (b). The fault is discretized along dip in 20 subfaults, and the input slip (i.e., the target) for each subfault is represented as a gray vertical line. For each subfault, the posterior PDFs of coseismic ( $a$ and $b$ ) and postseismic ( $c$ and d) slip is colored according to the offset between the target parameter and the posterior mean, with a color scale saturated at $50 \mathrm{~cm}$ for the coseismic slip and at $5 \mathrm{~cm}$ for the postseismic slip. The target slip is well inferred if the PDF of a particular parameter is colored in dark blue, while it is not if the PDF is colored in red. CTW $=$ Combined Time Windows; PDF $=$ probability density function.

(e.g., Anzidei et al., 2009; Atzori et al., 2009; Balestra \& Delouis, 2015; Cheloni et al., 2010, 2014; Cirella et al., 2012; D'Agostino et al., 2012; Trasatti et al., 2011; Volpe et al., 2015). To avoid the contamination of coseismic signal by early afterslip, Yano et al. (2014) proposed to explore independently the early postseismic deformation, yet with data sets covering different time intervals (1 day after the mainshock for GNSS, 6 days for InSAR). Significant postseismic displacement is recorded up to several months after the mainshock (e.g., Albano et al., 2015; Cheloni et al., 2014; D'Agostino et al., 2012; Gualandi et al., 2014), yet most studies of long-term postseismic signal did not analyze the first few days of postseismic deformation.

\subsection{Data, Forward Model, and Prior Information}

From a geodetic perspective, this event has been particularly well documented. We can distinguish two main static data sets: one which is strictly coseismic (co, using continuous GNSS data), and the other which also includes several days of postseismic slip (co+post, using cGNSS and InSAR). Two SAR images were acquired 6 days after the mainshock rupture, making the L'Aquila earthquake a perfect case study for our proposed approach. The co data set corresponds to surface displacements measured between the earthquake time 

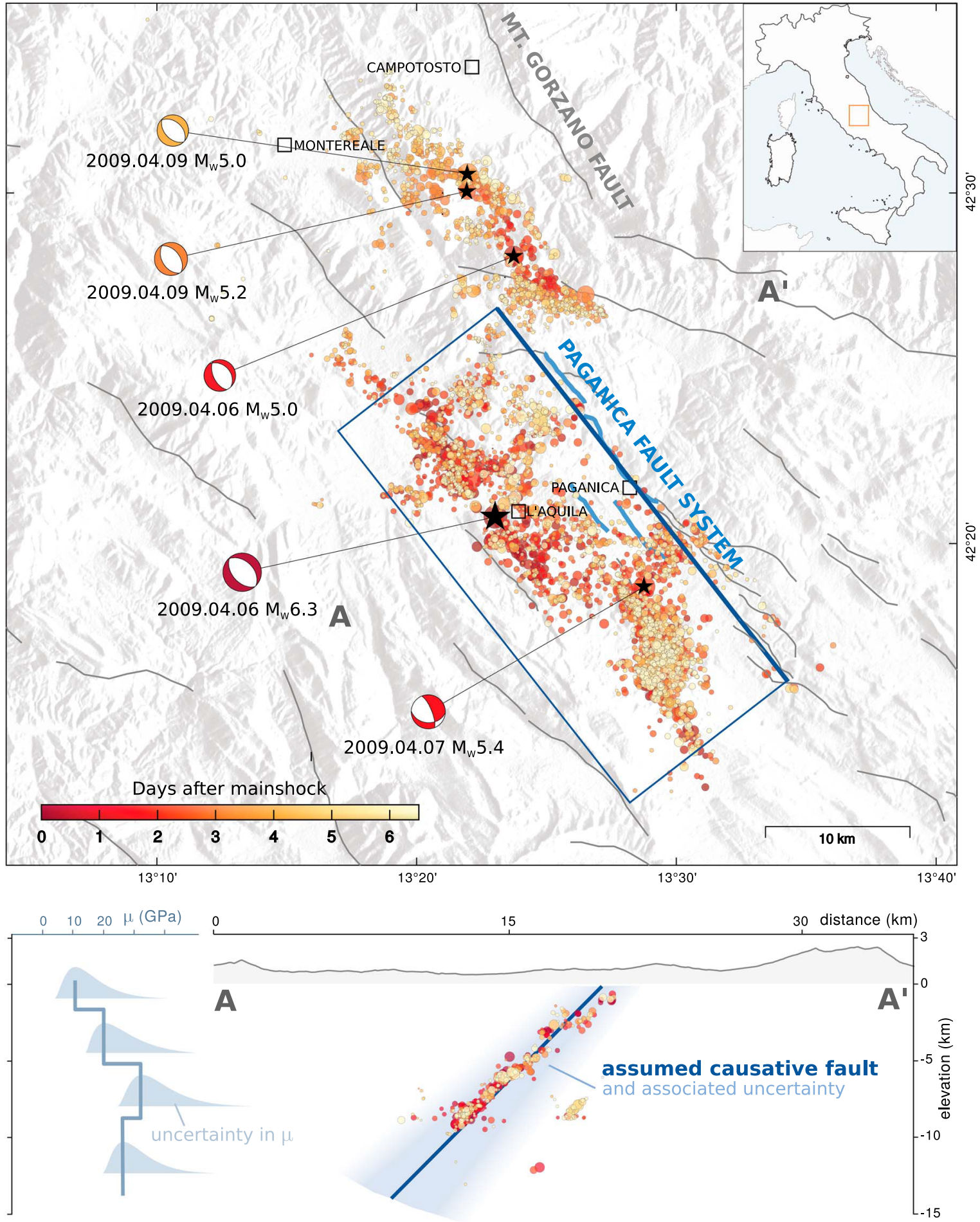

Figure 2. Seismotectonic framework of the area involved in the 2009 seismic sequence (top) and assumed forward model and associated uncertainties (bottom). In the map, colored circles are the aftershocks from 6 April 2009 at 01:32 UTC to 12 April 2009, from the catalog of Valoroso et al. (2013). The aftershocks are colored from their occurrence time after the mainshock. Beach balls are the focal mechanisms of the mainshock and four main aftershocks, with their respective epicenters located by black stars. Solid gray lines are the major seismogenic faults of the area (Boncio et al., 2004a; Lavecchia et al., 2012). The observed coseismic surface rupture is indicated with continuous blue lines (Boncio et al., 2010). Our assumed fault geometry is shown with a dark blue rectangle. In the elevation profile (bottom), uncertainty in the fault geometry is illustrated in blue. The assumed elastic modulus $\mu$ and associated uncertainties are also illustrated for the first $12 \mathrm{~km}$ below the Earth surface. 
occurrence $\left(t_{0}\right)$ and 25-30 s after $t_{0}$ and includes the static offsets of 41 (including high rates) GPS stations surrounding the earthquake area processed by Avallone et al. (2011). The co+post data set covers the coseismic phase plus 6 days of postseismic slip, documented by 40 static GPS offsets and 2 InSAR frames: an ascending COSMO-SkyMed frame and a descending Envisat frame (Table S1). The observations and their processing are detailed in the supporting information (Text S1; Jolivet et al., 2012; Lohman \& Simons, 2005; Rosen et al., 2004).

The Paganica fault is generally thought to be responsible for the coseismic rupture of the L'Aquila earthquake and also for most of its postseismic deformation (Cheloni et al., 2014; D'Agostino et al., 2012; Yano et al., 2014) along with the northernmost Campotosto fault (Figure 2; Gualandi et al., 2014). Although the distribution of relocalized aftershocks and surface rupture suggest that the Paganica fault system is possibly segmented (Boncio et al., 2010; Lavecchia et al., 2012) and/or curved at depth (Chiaraluce et al., 2011; Lavecchia et al., 2012; Valoroso et al., 2013), its geometry remains poorly constrained below the surface. The variability of published morphologies for the causative fault (Lavecchia et al., 2012) suggests that even with a large amount of observations and a great seismotectonic knowledge of the area, it is not possible to determine a unique fault geometry. This is why we approximate the Paganica fault geometry as a planar surface. We determine strike and position from the trace of the coseismic surface rupture (Boncio et al., 2010; EMERGEO Working Group, 2010) and formerly identified seismogenic faults (e.g., Boncio et al., 2004b). We select the dip and width based on aftershock relocations and focal mechanisms (e.g., Chiaraluce et al., 2011, 2012; Valoroso et al., 2013). Hence, our preferred geometry extends over $25 \mathrm{~km}$ south of coordinates $\left(13.386^{\circ} \mathrm{E}, 42.445^{\circ} \mathrm{N}\right)$ with a strike of $\mathrm{N} 142^{\circ}$. We set fault dip at $54^{\circ}$ and width at $18 \mathrm{~km}$, such that the fault is reaching the ground surface. This geometry is in agreement with already proposed causative structures (e.g., Lavecchia et al., 2012). The fault is divided into 154 subfaults of 1.8-km length and 1.6-km width. As our fault geometry does not reflect the reality and is poorly constrained, we account for its uncertainties (Ragon et al., 2018, 2019) and assume a standard deviation on the fault dip of $5^{\circ}$ and on the fault position (the fault position varying perpendicularly from the fault trace) of $1.5 \mathrm{~km}$, regarding the discrepancies between published fault models (e.g., Lavecchia et al., 2012). We do not account for uncertainties in the fault strike for simplicity, and because its influence might be small when uncertainty in the fault position is already acknowledged (Ragon et al., 2019).

We perform the static slip inversion assuming a 1-D layered elastic structure derived from the CIA velocity model (Herrmann et al., 2011) and calculate Green's functions with the EDKS software (Zhu \& Rivera, 2002). We precompute Green's functions at depths intervals of $500 \mathrm{~m}$ down to $15-\mathrm{km}$ depth and every $5 \mathrm{~km}$ below. Laterally, the Green's functions are computed every kilometer to reach the maximum epicentral distance of $100 \mathrm{~km}$. Then, we interpolate and sum precomputed Green's functions given our fault geometry and data locations. The strong variability in published elastic models for the central Italy (Herrmann et al., 2011) can have a strong influence on coseismic slip estimates (e.g., Gallovic et al., 2015; Trasatti et al., 2011; Volpe et al., 2012). We thus account for the uncertainties in our Earth model (Duputel et al., 2014) assuming a standard deviation on shear modulus of $4 \%$ at depths greater than $15 \mathrm{~km}$ and $13 \%$ above. These values have been chosen a priori considering the variability between layered models and the horizontal variability of 3-D crustal models for several depth intervals (Magnoni et al., 2014).

We perform our static slip inversion as previously detailed in section 2 . We specify prior distributions for each model parameter: a zero-mean Gaussian prior $p(\mathbf{m})=\mathscr{N}(-10 \mathrm{~cm}, 10 \mathrm{~cm})$ on the strike-slip component (we assume that, on average, the slip direction is along dip) and we consider each possible value of dip-slip displacement equally likely if it does not exceed $20 \mathrm{~cm}$ of reverse slip and $5 \mathrm{~m}$ of normal slip: $p(\mathbf{m})=\mathscr{U}$ $(-20 \mathrm{~cm}, 500 \mathrm{~cm})$.

\subsection{Coseismic and Early Postseismic Slip Models}

We will start by analyzing models inferred by the independent approach as applied to the two data sets. The first model is inferred from co data (model COgps), and the second is estimated from the co+post data set (model COPOST). The co+post data set is similar to what has been used in several previous studies to infer the coseismic slip (D'Agostino et al., 2012; Cheloni et al., 2014; Cirella et al., 2012; Volpe et al., 2015; Yano et al., 2014). The results of these two inversions will then be compared to those of the CTW inversion. For the sake of comparison, these inversions are performed without accounting for epistemic uncertainties. This refinement will only be added in a final inversion. 
For each approach, we estimate 300,000 samples from among the most plausible models of the full solution space. This set of samples provides information on the possible parameter values and on their uncertainty. Mean and median models are basic probabilistic values but can give a good overview of the range of the most likely solutions. More detailed quantities, such as the marginal posterior distribution of a given parameter or the variability of slip between neighboring subfaults, will inform on the uncertainties associated with individual model parameters and trade-offs between parameters. However, the interpretation of average and median samples should be taken with caution: The mean model does not reflect the uncertainty of inferred parameters, nor does it reproduce the covariance between parameters.

As we are tied to the need of presenting our results with 2-D figures when the exploration is done on a parameter space with tens of dimensions, we choose to represent our results in three different ways. For the first representation (e.g., Figures 3a-3d, 5a, and 5b), we divide our set of 300,000 samples into 25 families and represent the median model of each family as subdivisions of subfaults (each subfault is thus divided in 25 pixels, more information in Figure S3). The first family gathers samples with parameters of less than $50 \mathrm{~cm}$ offset from the mean model parameters. Other families are built iteratively around a randomly selected model that has not fitted within antecedent families, except for the last family which regroups orphan samples). This first representation illustrates the variability in slip amplitude for a particular parameter. Also, it allows for a visual estimation of the covariance between neighbor parameters: If samples that infer large dip slip on a subfault infer small dip slip on its neighbor subfault, and vice versa, then there is a trade-off between these two parameters.

A second representation shows the posterior marginal PDFs of the dip-slip parameters which, for a particular parameter, will inform on the amount of slip uncertainty associated to each subfault (e.g., Figures $3 \mathrm{e}-3 \mathrm{~g}$ and $5 \mathrm{c}-5 \mathrm{e})$. In particular, the shape and width of the posterior PDF can be considered as a proxy of the model resolution for the inferred parameter.

The third representation is a classic map view of the dip-slip amplitude and rake of the mean model (e.g., Figures S4a, S4b, S8a, S8b, S12a, and S12b).

\subsubsection{Approaches Assuming Independent Data Sets}

When solving for the model COgps, we find that most of the slip is concentrated in the shallow parts of the fault (Figures 3a, S4a, S4c, and S4e). Slip amplitudes reach $230 \mathrm{~cm}$ in the first $2 \mathrm{~km}$ below the Earth surface. These values largely contradict field observations hardly reporting more than $15 \mathrm{~cm}$ of surface offset (Falcucci et al., 2009; Vittori et al., 2011). This contradiction probably derives from our limited set of observations, with only four GPS stations documenting the rupture in the near field (Figure 4a). The COgps model is thus largely underdetermined and unlikely to represent a reliable image of the coseismic deformation. In contrast, the COPOST slip model is inferred from a more populated data set extending over a large part of the Paganica fault (Figure 3b and S4b). The patch of highest slip amplitude, reaching more than $150 \mathrm{~cm}$, is well constrained and located between 5- and 7-km depth (Figure 3b). Up to 100-cm slip is also inferred below the hypocenter. The inferred slip is almost purely dip slip (Figure S4b, S4d, and S4f). The scalar seismic moment of model COPOST, calculated with $\mu=3.510^{10}$, is $M_{0}=4.9 \pm 0.6710^{18} \mathrm{~N} \cdot \mathrm{m}$. This value corresponds to a $M_{w} 6.4$ earthquake rather than a $M_{w} 6.3$.

The comparison between observations and predicted surface displacement is shown in Figure 4 for the GPS data sets and in Figure S5 for the interferograms. As expected, the COgps model well explains the co data set (Figure $4 \mathrm{~b}$ ), but its predictions hardly fit the interferograms of the co+post data set (Table S2). In contrast, the predicted surface displacement of the COPOST model well approaches the co+post observations (Figures 4b and S5), with limited residuals (Table S2). The surface displacement that happened up to 6 days after the mainshock is similar when estimated with GPS or with the ENVISAT interferogram (Figure S6). Yet, the displacement measured with the COSMO-SkyMed interferogram differs from the one measured with GPS, particularly for the high-rate GPS station CADO (Figure S7). This misfit could be related to unwrapping errors or effects that have not been completely corrected, explaining why the COSMOSkyMed data are systematically less well fitted by predictions than other observations.

\subsubsection{Dual Time Approach, Without Epistemic Uncertainties}

With the CTW approach, we infer two slip models: the strictly coseismic model sCO (see Figures 3c, S8a, S8c, S8e, and S9 for an animated compilation of probable models) and the model sPOST which reflects the 6 days displacement following the mainshock (Figures 3d, S8b, S8d, and S8f). The model sCO, exploiting 


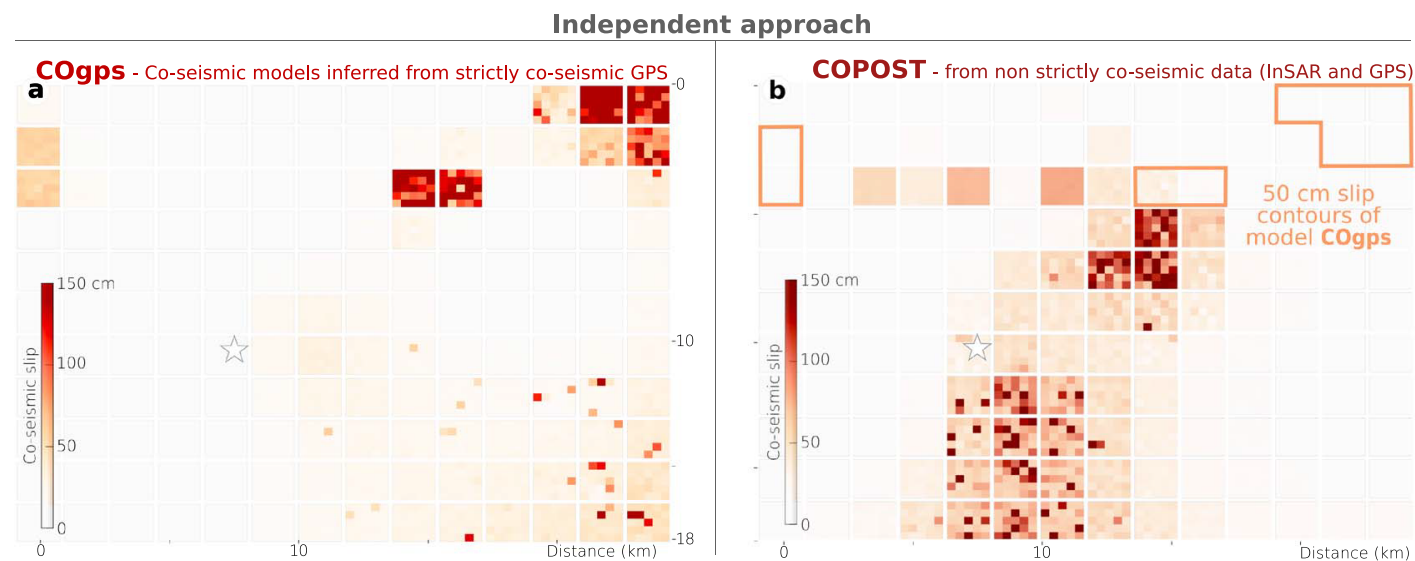

CTW approach models inferred from both strictly co-seismic and co+post datasets

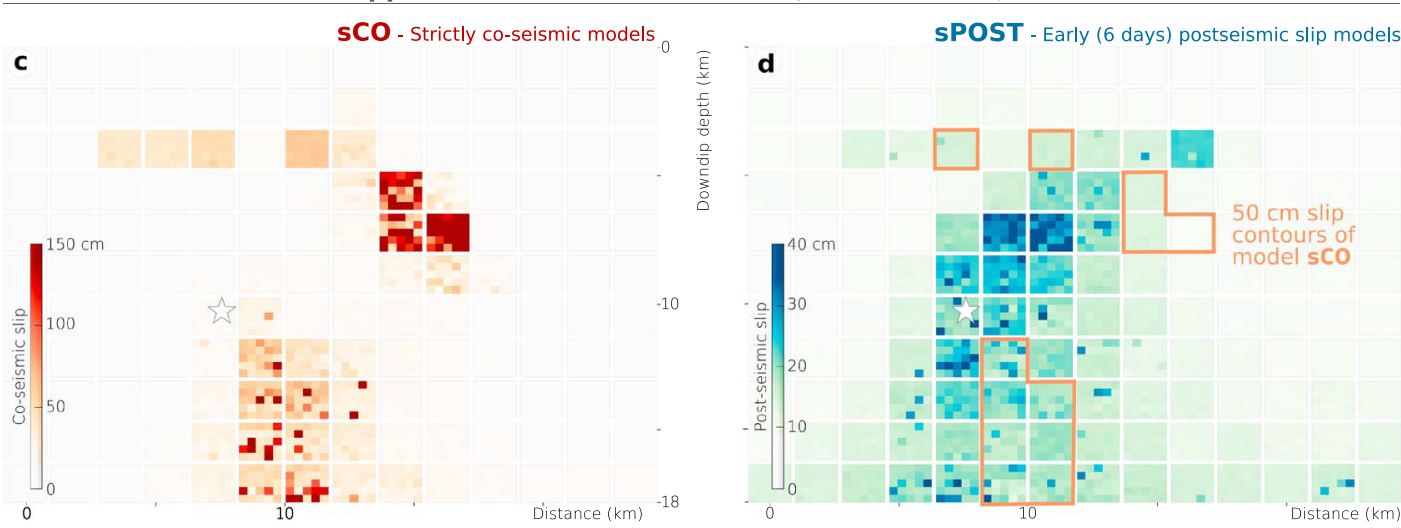

Variability between models COPOST and sCO

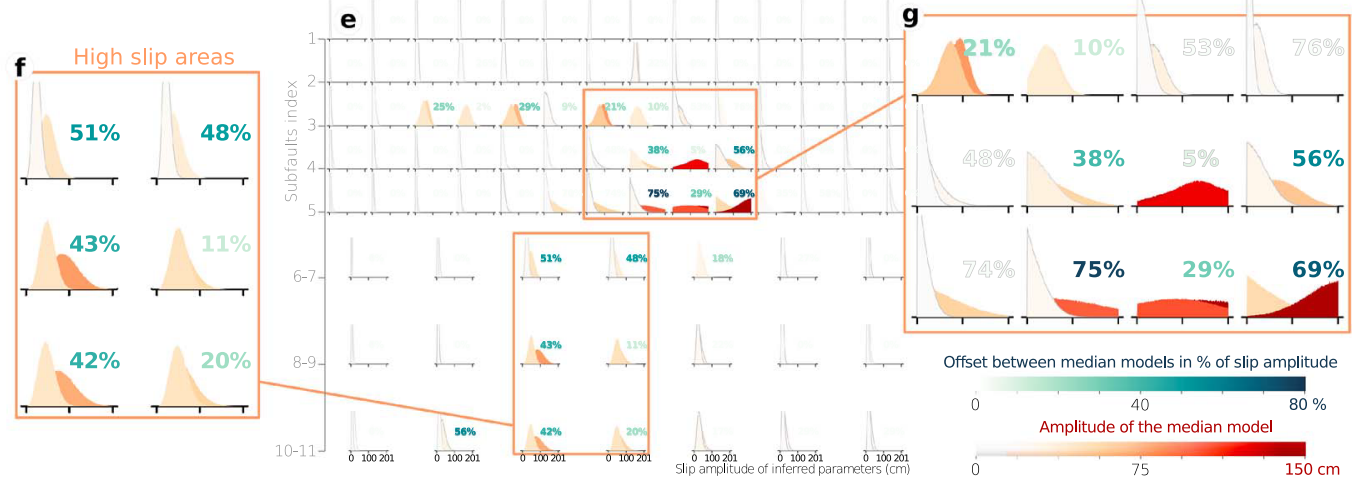

Figure 3. Comparison between finite-fault models inferred with the independent or the CTW approach. (a) Strictly coseismic (30 s after the mainshock) slip model, named COgps, inferred from the strictly coseismic data set (GPS only). (b) Nonstrictly coseismic model COPOST inferred from the coseismic data set contaminated with some postseismic deformation. (c and d) Strictly coseismic sCO and early postseismic sPOST (6 days after the mainshock) slip models inferred jointly with the CTW approach. (a) to (d) illustrate the slip amplitude of the median models (norm of the slip vector) of 25 families of inferred models (more information in the text and Figure S3). Each subfault (large square) is divided into 25 pixels colored from the slip amplitude of the corresponding median model. (e) Comparison between the posterior probability density functions of the dip-slip parameters of models COPOST (b) and sCO (c), colored from the amplitude of their median model. In the last four rows, the PDFs have been merged, covering two subfaults along strike and two subfaults along dip (i.e., patches 2 times bigger than for the first four rows). The COPOST model PDFs are in the background, while the sCO PDFs are in the foreground. The offset between the median models is shown as percentage with a different color scale. Two high slip areas are illustrated in detail: the highest slip patch (g) and the deep slip patch (f). The plots of the posterior PDFs are truncated between 0 and $200 \mathrm{~cm}$ to simplify the visualization. CTW $=$ Combined Time Windows. 

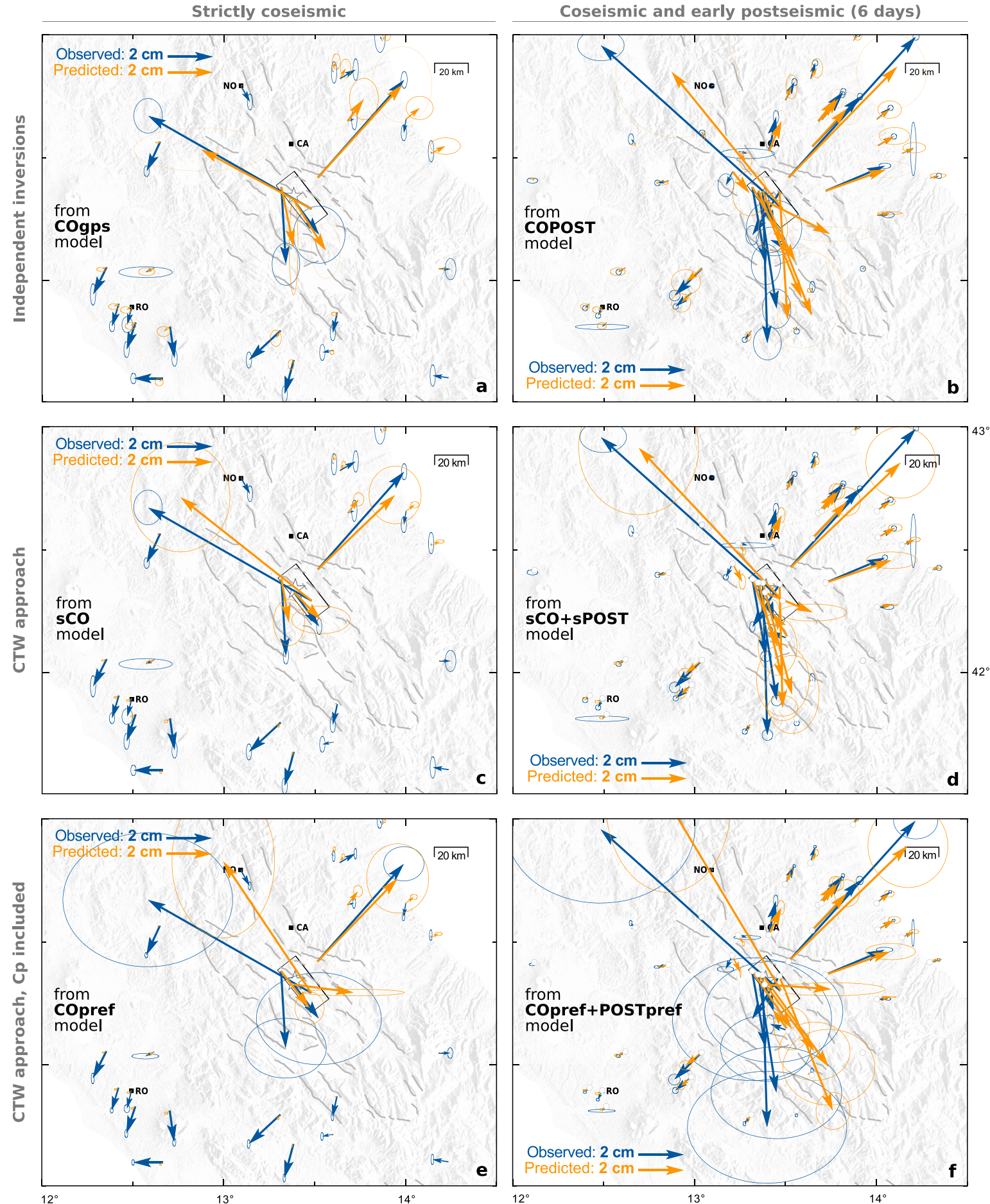

Figure 4. Comparison of horizontal surface displacement at GPS stations. Strictly coseismic displacement is shown on the left, while "co+post" displacement is shown on the right. Observed surface displacement is in blue with 95\% confidence ellipses. Predictions are in orange with 95\% confidence ellipses. In the top and middle rows, observational confidence ellipses (in blue) include only data errors. (a and b) The predictions have been calculated independently: using "co" data (a) and the co+post data set (b). (c and d) Predictions are derived from the CTW approach. (e and f) The predictions for a similar inversion setup, except epistemic uncertainties have been added to the data errors, enlarging the confidence ellipses. Our fault geometry is shown with a black rectangular box. The cities of Norcia (NO), Campotosto (CA), and Roma (RO) are indicated with black squares. Major seismogenic faults are shown in gray solid lines, and the epicenter is the white star. CTW $=$ Combined Time Windows. 
CTW approach accounting for epistemic uncertainties

a

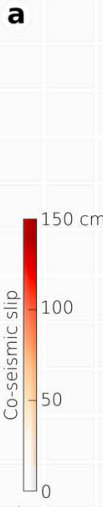

o
COpref - Strictly co-seismic models

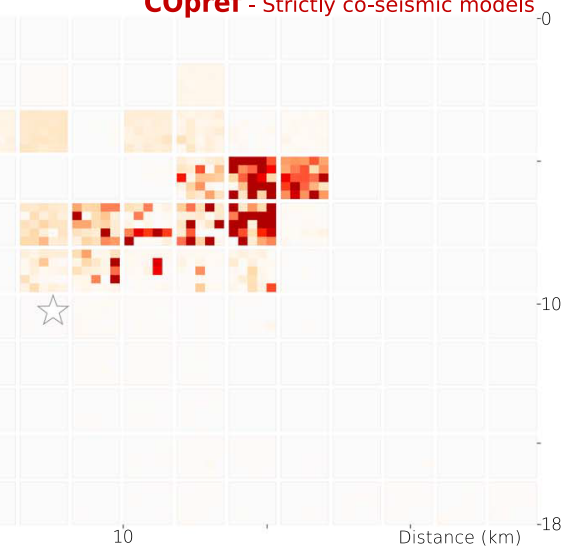

b

POSTpref - Early ( 6 days) postseismic slip models

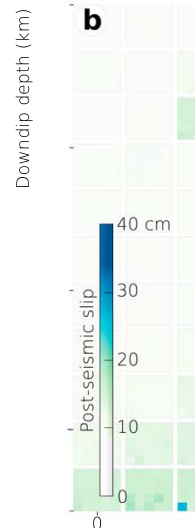

most probable post-seismic slip

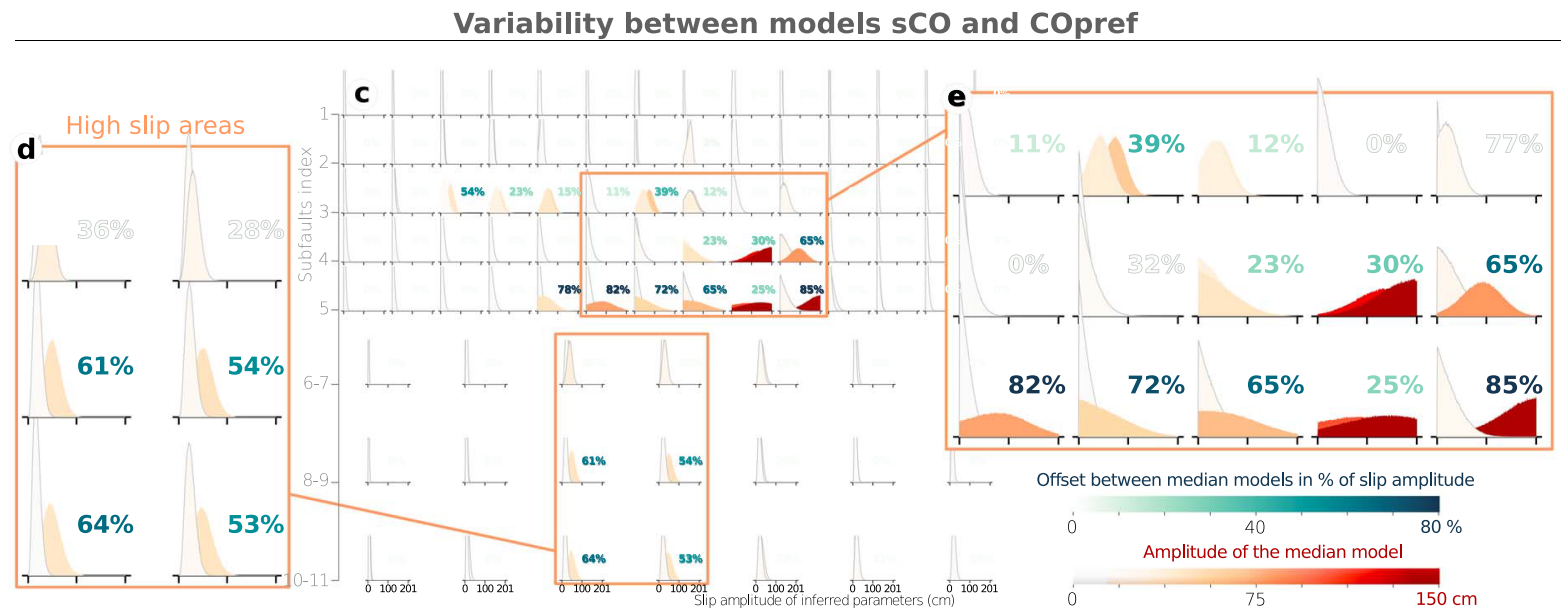

Figure 5. (a) and (b) Strictly coseismic COpref and early postseismic POSTpref (6 days after the mainshock) preferred slip models (norm of the slip vector), inferred with the CTW approach and accounting for epistemic uncertainties. (c) Comparison between the posterior probability density functions of the dip-slip parameters of models COpref (a) and sCO (Figure 3c), colored from the amplitude of their median model. In the last four rows, the PDFs have been merged, covering two subfaults along strike and two subfaults along dip (i.e., patches 2 times bigger than for the first four rows). The COpref model PDFs are in the foreground, while the sCO PDFs are in the background. The offset between the median models is shown as percentage with a different color scale. Two high slip areas are illustrated in detail: the highest slip patch (e) and the deep slip patch (d). The plots of the posterior PDFs are truncated between 0 and $200 \mathrm{~cm}$ to simplify the visualization. CTW $=$ Combined Time Windows.

information from both the co and co+post data sets, is in agreement with the main characteristics of the COPOST model (Figure 3b): The location, rake, and amplitude of the maximum slip patch are comparable (Figures S8a, S8c, and S8e), and a large amount of slip is also inferred at depth, up to $75 \mathrm{~cm}$ on average and exceeding $150 \mathrm{~cm}$ for some models (Figure 3c). However, unlike the COPOST model, the two main slip patches of the sCO model are delimited by an unruptured area (Figure 3c). Overall, the two models differ on average by $44 \%$ and by up to $75 \%$ for some subfaults characterized by high slip amplitudes (Figures 3e-3g and S10), mainly because of the variability of the amount of slip inferred below 5-km depth. For the model sCO, $M_{0}=3.50 \pm 0.6310^{18} \mathrm{~N} \cdot \mathrm{m}$ and is equivalent to a moment magnitude of 6.3 , corresponding to the GCMT value of 6.3.

With the CTW approach, we also find that a large portion of the fault slipped during a 6-day time window after the mainshock (Figure 3d), with maximum amplitude of $30 \mathrm{~cm}$ in the dip-slip direction (Figure S8b). The largest postseismic slip (>45 cm) is located between the coseismically ruptured patches (Figure 3c) and is well constrained with only $15 \mathrm{~cm}$ of posterior uncertainty (Figure S8f). Overall, postseismic slip ( $30 \mathrm{~cm}$ and below) tends to locate around the highest coseismic slip patch and the hypocenter but also overlaps the deepest coseismic slip patch. Yet, below 10-km depth, the posterior uncertainty can reach $100 \%$ of 

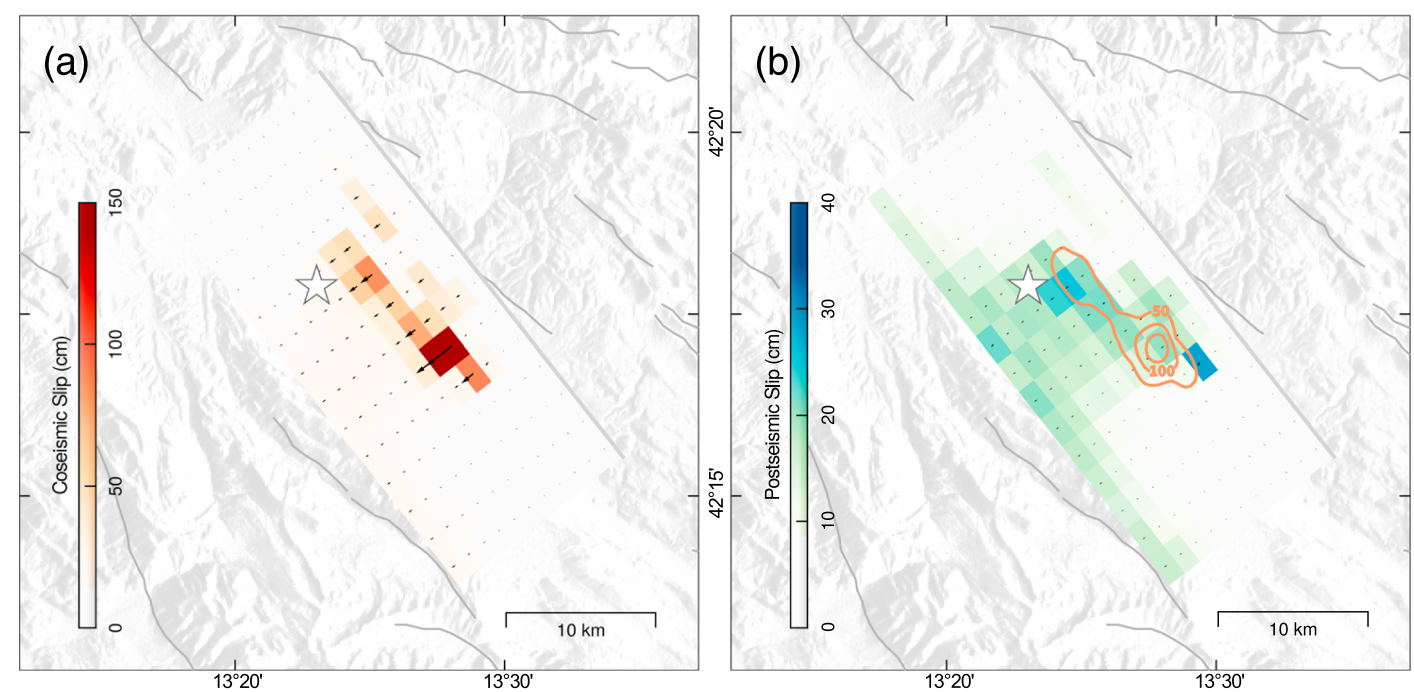

Figure 6. Our preferred slip models of the L'Aquila earthquake, inferred with the Combined Time Windows approach and accounting for epistemic uncertainties. ( $a$ and b) The dip-slip amplitude and rake of the average model in map view, the hypocenter being the white star. In (b), orange lines also show the 50-cm coseismic slip contours.

the median slip amplitude, meaning that the resolution is poor and that it is difficult to interpret anything at that level of detail (Figures S8d and S8f). The seismic moment of model sPOST is $M_{0}=1.58 \pm 0.6310^{18} \mathrm{~N} \cdot \mathrm{m}$. The predicted surface displacements fit well the observations (Figures $4 \mathrm{c}, 4 \mathrm{~d}$, and S11) with residuals similar to the ones of the COPOST model (Table S2).

As expected, the areas of largest postseismic slip in the SPOST model correspond to the locations of largest divergence between COPOST and sCO models (Figures 3b-3g). In summary, the usual approaches using independent data sets do not allow us to infer reliable images of the strictly coseismic and early postseismic phases. Whereas the co+post slip model is reliable, the co model is not robust enough to retrieve the early afterslip from the subtraction of these two slip distributions. Additionally, the scalar seismic moment of model co+post corresponds to a moment magnitude greater than the GCMT $M_{w}$ of 6.3. In contrast, the CTW approach allows us to infer robust estimates of both coseismic and postseismic slip, to exploit all the information collected within our geodetic observations, and to correctly estimate the seismic moment. However, the reliability of these models can be questioned as they do not account for uncertainties in the forward model.

\subsubsection{Dual Time Approach, Accounting for Epistemic Uncertainties}

Here, we present the results of the CTW approach, as in the previous section but accounting for epistemic uncertainties. We will name the resulting models COpref and POSTpref since they correspond to our preferred approach providing the most complete and objective evaluation of the problem (see Figures 5, 6, S12, and S14 for an animated compilation of probable coseismic models). The distribution of the coseismic slip differs by $42 \%$ on average and by up to $88 \%$ locally from the models inferred without accounting for uncertainties (Figures $5 \mathrm{c}$ and S13). The coseismic slip is now limited (on average) to a single 10-km-long patch located between 5- and 10-km depth, reaching more than 150-cm amplitude to the south (right-hand side of Figure 5a), with a rake of $90^{\circ}$ that does not vary along the patch (Figure 6a). The corresponding scalar seismic moment $M_{0}=3.03 \pm 0.6410^{18} \mathrm{~N} \cdot \mathrm{m}$ is slightly lower than what was estimated for the model sCO but is still very close $\left(M_{w}=6.28 \pm 0.06\right)$ to the (GCMT) value of $M_{w} 6.3$.

Compared to the COpref model, the main characteristics of the POSTpref model are not strongly affected by the inclusion of uncertainties. Overall, postseismic slip ( $20 \mathrm{~cm}$ and below) occurs mostly below the coseismic high slip patch, where almost no (less than $20 \mathrm{~cm}$ ) coseismic slip is imaged. Subfaults with the largest postseismic slip (more than $40 \mathrm{~cm}$, almost purely dip slip as shown in Figure 6b) tend to be located around or on the edges of the coseismic high slip patch (Figure $5 b$ ). The presence of large postseismic slip below 10-km depth is unlikely as the posterior uncertainty reaches $150 \%$ of the median slip (the resolution is poor at depth, Figure S12). Thus, only three narrow zones most probably slipped postseismically (see Figure 5b, and a 

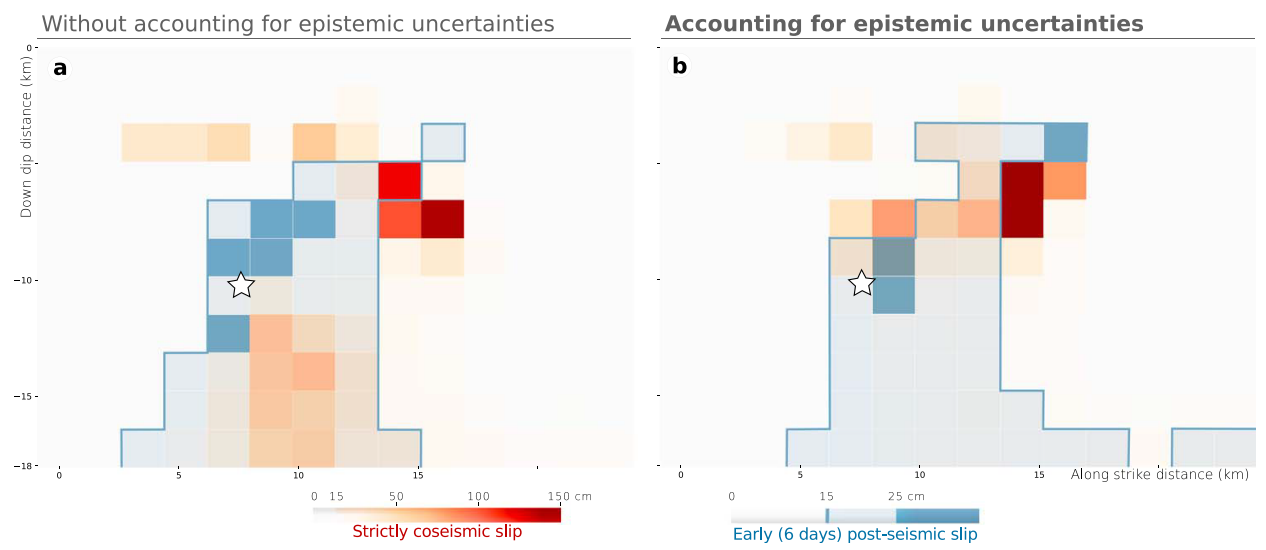

Figure 7. Effect of epistemic uncertainties $\left(\mathbf{C}_{\mathrm{p}}\right)$ on the distribution of strictly coseismic slip and afterslip. The slip models (sum of median strike- and dip-slip components) have been inferred accounting for epistemic uncertainties (b) or not (a). The strictly coseismic slip median model is in light gray to dark orange color scale. The subfaults that slipped more than 15 and $25 \mathrm{~cm}$ up to 6 days after the mainshock, according to our median model, are in transparent light and medium blue, respectively. The afterslip does not overlap the coseismic slip when $\mathbf{C}_{\mathrm{p}}$ is accounted for (b), whereas the two slip distributions overlap at depth when no $\mathbf{C}_{\mathrm{p}}$ is included (a).

comparison of median and maximum a posteriori models in Figure S15). $M_{0}$ is similar to model sPOST with a value of $1.60 \pm 0.6310^{18} \mathrm{~N} \cdot \mathrm{m}$. The addition of epistemic uncertainties has increased the residuals between observations and predictions (see Table S2 and Figure S16). This behavior was expected as the inclusion of $\mathbf{C}_{\mathrm{p}}$ allows the inversion to tolerate for larger misfits at data points where the forward model predictions are less reliable (Ragon et al., 2018, 2019).

In summary, the CTW approach shows that if early postseismic is not acknowledged as postseismic signal, coseismic models may be biased by more than $40 \%$ on average and of up to $75 \%$ locally. But we also learn from these different tests that adding more data into the problem is not sufficient, and epistemic uncertainties remain critical for the inference of a reliable model. Altogether, our results emphasize the need to account for two types of bias in the slip models: the contamination of coseismic observations by some early postseismic signal and not acknowledging the uncertainties associated with the forward problem.

\section{Discussion}

\subsection{Discussion of the CTW Approach}

Observations of coseismic or postseismic processes are often contaminated by other sources of deformation (mainly postseismic or coseismic, respectively) and are widely used, as noncontaminated data are rare and scarcely distributed. Optimizing the use of the information content in each data set is thus critical to improve the robustness of both coseismic and postseismic slip models. A first approach would be to account for potential uncertainties in the coseismic model due to early afterslip in the form of a covariance matrix, as already proposed in Bletery et al. (2016). While this approach helps inferring more reliable coseismic models at a low computational cost, it does not allow us to estimate the early afterslip and needs a prior evaluation of the amount of afterslip considered as coseismic signal. Another strategy would be to jointly infer co and co+post data as if they were strictly coseismic and to select models that better explain the co observations, as in Chlieh et al. (2007). In this case, the computational cost is increased because several models have to be tested. Additionally, with these approaches the early postseismic slip is not estimated. In contrast, the CTW approach we use in this study allows us to discriminate coseismic from early postseismic slip and to reliably estimate corresponding slip models, as suggested also by the results of Floyd et al. (2016) and Walters et al. (2018). The CTW approach takes advantage of the InSAR data that recorded both coseismic and postseismic deformation to help constrain both strictly coseismic and early postseismic models.

Our results on the L'Aquila event show that the early afterslip, here corresponding to 6 days after the coseismic rupture, can reach a fourth to a third of the amplitude of the coseismic slip. If the early afterslip is acknowledged as coseismic signal, coseismic models of the L'Aquila event are biased. The impact of early 


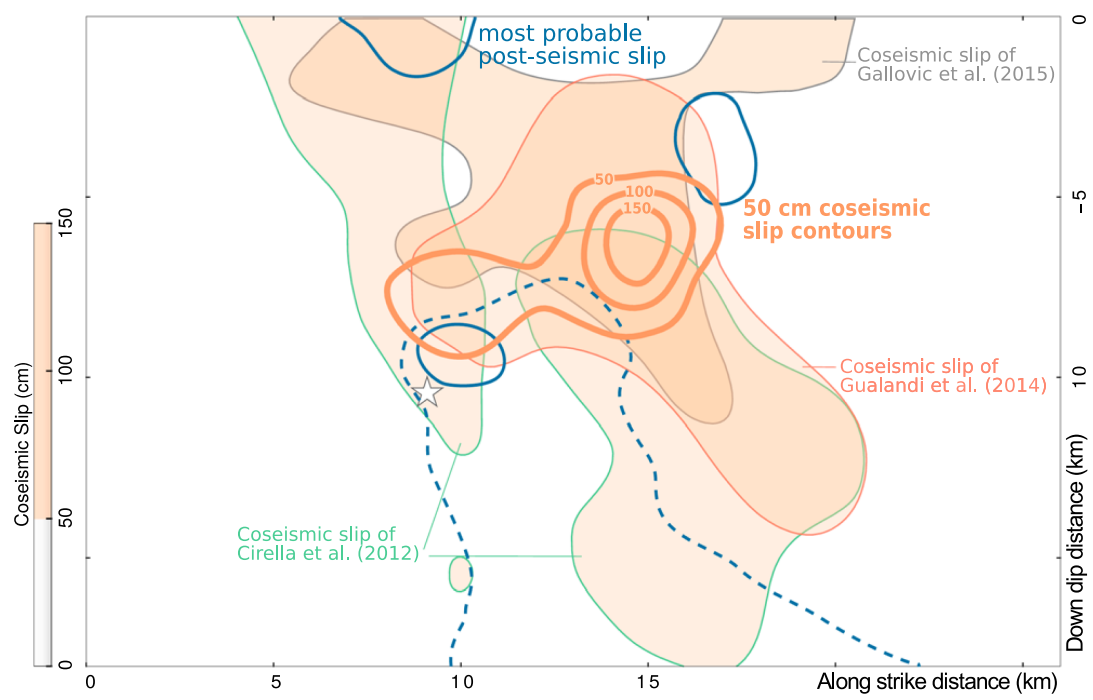

Figure 8. Comparison between the slip distributions inferred with the Combined Time Windows approach and coseismic slip distributions of other studies. The strictly coseismic slip of Gualandi et al. (2014) inferred from GPS only, the strictly coseismic slip of Gallovic et al. (2015) inferred from accelerometric and high-rate GPS data, and the coseismic slip of Cirella et al. (2012) inferred from GPS, InSAR, and strong motion are projected in our fault plane in transparent light orange when slip exceeds $50 \mathrm{~cm}$. The 50 -cm contours of our strictly coseismic slip distribution and the 15 -cm contours of our afterslip inferred accounting for epistemic uncertainties are in bold lines, respectively orange and dark blue. The area of afterslip delimited with a dashed blue line is considered as less plausible as inferred with large uncertainties. The hypocenter is the white star.

afterslip on the coseismic models is particularly large in the case of the L'Aquila event and questions the generic nature of this result. Overall, early afterslip remains poorly studied but has been shown to range from $0.6 \%$ to more than $8 \%$ of the coseismic peak slip in the first 3-4 $\mathrm{hr}$ following an earthquake (respectively for the 2009 great Tohoku-Oki earthquake and the $2012 M_{w} 7.6$ Nicoya earthquake, Munekane, 2012; Malservisi et al., 2015). Twardzik et al. (2019) also conclude that coseismic models may be biased by more than $10 \%$ if the early postseismic deformation is neglected. Thus, that the postseismic deformation ongoing 6 days after the mainshock reaches up to $20 \%$ of the coseismic slip of the L'Aquila earthquake might not be an extreme case.

Our tests also demonstrate that models are largely impacted by the introduction of epistemic uncertainties (Figure 7). This impact could mean the assumed fault and Earth properties are not realistic enough to capture the real seismic rupture and/or that small variations of the fault geometry (slight curvature and roughness) or of the Earth model (3-D heterogeneities) largely affect our slip models. The influence of epistemic uncertainties is greater on the coseismic model, as expected from the fact that these uncertainties scale with the amount of slip (Duputel et al., 2014; Ragon et al., 2018). Accounting for uncertainties of the forward model allowed us to exclude the possibility of deep slip for the coseismic models, but not totally for the postseismic models probably because of the much lower slip amplitudes. Additionally, accounting for $\mathbf{C}_{\mathrm{p}}$ prevented the most probable coseismic and postseismic slips to overlap in deeper parts of the fault. The inclusion of epistemic uncertainties acts like a smoothing constraint on the slip distribution, but with a smoothing factor being controlled by the inaccuracies of the forward problem.

\subsection{Nonuniqueness of Coseismic and Afterslip Models of the L'Aquila Earthquake}

Our results on the L'Aquila event indicate that the strictly coseismic slip is concentrated in a thin horizontal band located between 5- and 7-km depth and reaching more than $150 \mathrm{~cm}$ in amplitude at its southern end, with no large slip amplitudes inferred below 8-km depth (Figures 6 and 8). The highest amplitude is reached at about 6-km depth southwest of the hypocenter, a rupture area also imaged in the coseismic models of Gualandi et al. (2014), Gallovic et al. (2015), and Cirella et al. (2012) (inferred respectively from GPS only, from accelerometric and high rate GPS data, and from GPS, InSAR, and strong motion; see Figure 8) and most of other authors (Atzori et al., 2009; Balestra \& Delouis, 2015; Cheloni et al., 2014; D'Agostino et al., 

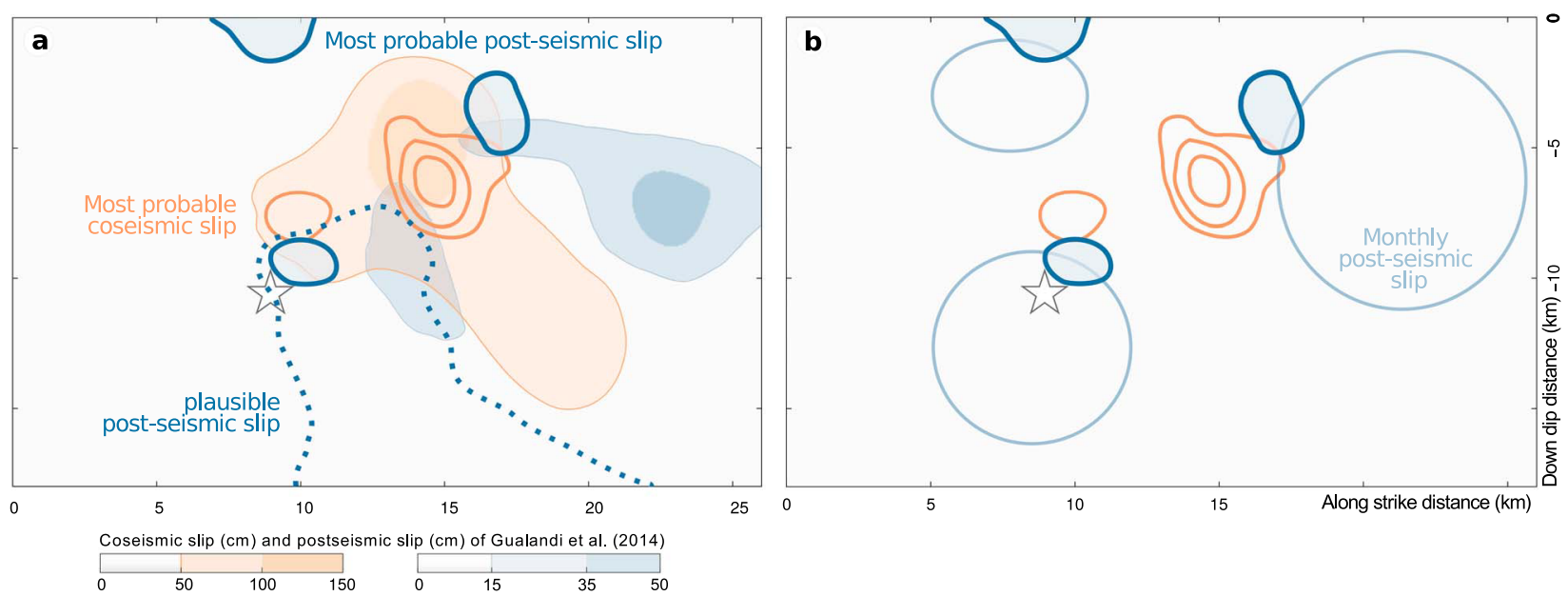

Figure 9. Comparison between our most probable strictly coseismic and postseismic slip distribution 6 days after the mainshock and the postseismic slip up to 306 days after the mainshock. (a) Our most probable slip distributions are represented with bold orange and dark blue lines, respectively, for coseismic (50-cm contours) and postseismic slip (slip $>10 \mathrm{~cm}$ ). The area of afterslip delimited with a dotted blue line is considered as less plausible as inferred with large uncertainties. The coseismic slip and afterslip 306 days after the mainshock inferred by Gualandi et al. (2014) are plotted with the same color codes but as color swaths. (b) Our results are compared to the area that slipped postseismically during about 6 months (176 and 194 days, respectively) after the mainshock as modeled by both D'Agostino et al. (2012) and Cheloni et al. (2014). The hypocenter is the white star.

2012; Serpelloni et al., 2012; Trasatti et al., 2011; Volpe et al., 2015). It is the only recurrent pattern we can notice between the four slip models of Figure 8. Indeed, while we do not image any shallow slip, other published slip models do with up to $1.5 \mathrm{~m}$ in amplitude (Figure 8; Cirella et al., 2012; Volpe et al., 2015). Our results suggest that this imaged shallow coseismic slip may rather be early postseismic slip (Figure 8). At greater depths, most authors infer large slip amplitudes, while our preferred model shows no slip below 8-km depth.

The imaged patches of postseismic slip $(>15 \mathrm{~cm})$ are located around our coseismic slip, near its hypocenter and southern end. Interestingly, our inferred postseismic slip is also located near areas that ruptured coseismically as inferred by other studies (Figure 8). The postseismic slip that occurred several days to months after the mainshock is characterized by three wide slip areas, located SW of the main coseismic slip patch, above the hypocenter close to the surface, and around the hypocenter (Cheloni et al., 2014; D'Agostino et al., 2012; Gualandi et al., 2014). Most of these postseismic models incorrectly treat the first days of postseismic signal as a coseismic deformation. While we infer likely afterslip in similar locations, the afterslip patches are limited to narrower areas near the coseismic rupture (Figure 9). Most of these longer-term postseismic models cover time periods ranging from 6 days to 9 months after the mainshock; they overlook a large part of the early postseismic deformation. Thus, the peak amplitude of the early afterslip is up to 3 times larger than what was imaged for several months by D'Agostino et al. (2012) and Cheloni et al. (2014).

Our results show that the amplitude and distribution of long-term afterslip may be largely underestimated (here by a factor of 3 ) if the deformation occurring the first few hours to days after the mainshock is not accounted for in the postseismic budget. Thus, overlooking the early part of the postseismic phase measured in geodetic data may bias not only the estimates of the coseismic slip but also our estimates of the postseismic phase.

\subsection{Fault Frictional Properties and Relationship Between Afterslip and Aftershocks}

The comparison between our early postseismic model and images of longer-term postseismic slip suggests that afterslip may nucleate preferentially around the coseismic rupture in the days following the mainshock (Figure 9b). Afterward, the afterslip propagates and extends, both along-dip and laterally, away from the coseismic slip (Cheloni et al., 2014; D'Agostino et al., 2012; Gualandi et al., 2014). This behavior agrees with models explaining afterslip as a result of rate dependent friction behavior. Indeed, in these models the afterslip relaxes the stress increment induced in velocity-strengthening area by the coseismic rupture (Marone et al., 1991; Perfettini \& Avouac, 2004). The postseismic sliding thus nucleates close to the mainshock 

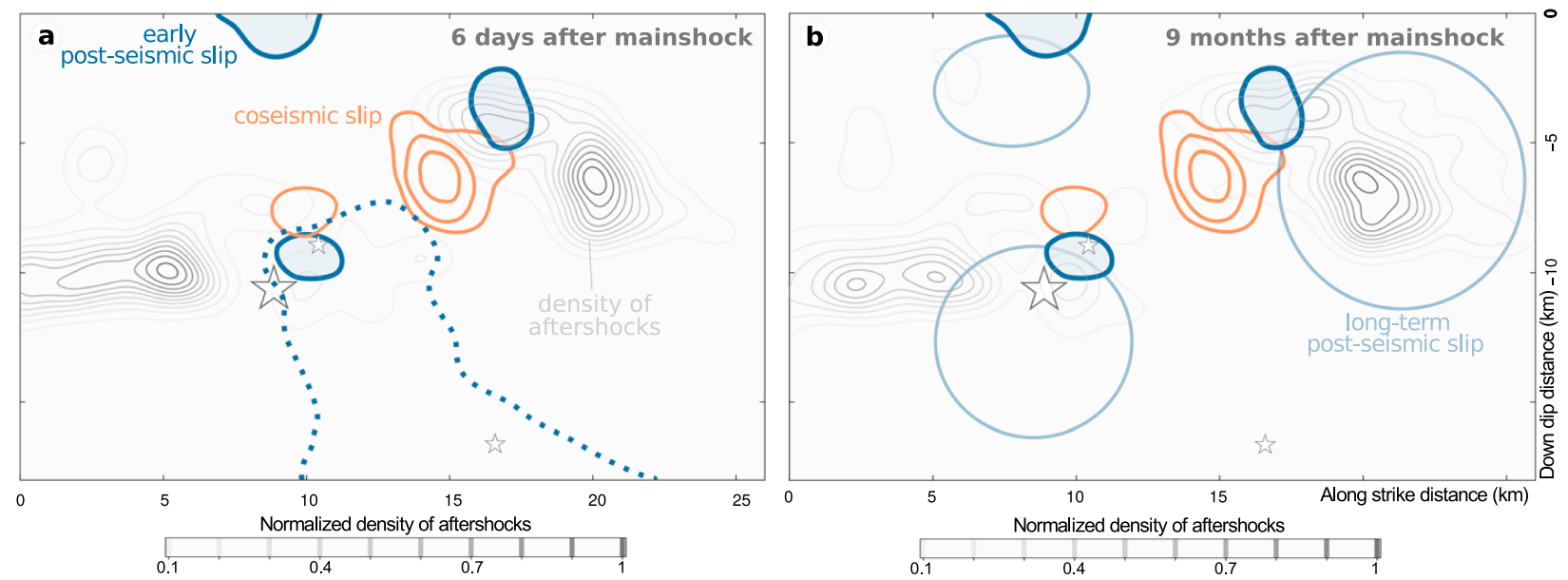

Figure 10. Distribution of most probable coseismic slip and afterslip models, and the normalized density of aftershocks that occurred (a) within 6 days after the mainshock or (b) up to 9 months after the mainshock $\left(M_{c}=0.88\right.$, catalog of Valoroso et al., 2013). The strictly coseismic 50-cm slip contours are in orange, while the contours of most probable afterslip (slip $>10 \mathrm{~cm}$ ) are in blue. The area delimited by dotted blue lines has plausibly hosted some afterslip, but not as probably as the other regions. The areas that slipped postseismically during about 6 months after the mainshock as modeled by D'Agostino et al. (2012), Cheloni et al. (2014), and Gualandi et al. (2014) are the blue circles. The density of aftershocks located within $3 \mathrm{~km}$ of the fault (to account for potential uncertainty of the fault geometry) is calculated with a kernel density estimation method (Parzen, 1962) with a smoothing factor of 0.6. The cumulated number of aftershocks of $M_{c}=0.88$ is of $\sim 6,000$ at 6 days after the mainshock and 8 times larger 9 months after the mainshock (Figure S17). The hypocenter and aftershocks of $M_{w} \geq 4.4$ are the white stars.

asperity and propagates with time outward from the rupture zone. That early afterslip relates to the stress changes induced by the coseismic rupture has also been modeled for other events (e.g., the $M_{w} 8.0$ Tokachi-oki, $M_{w} 7.6$ Chi-Chi, and the $M_{w} 6.0$ Parkfield; Chan \& Stein, 2009; Miyazaki et al., 2004; Wang et al., 2012, respectively).

Additionally, our results show that early afterslip nucleates within narrow areas (1-2 km wide) and does not happen everywhere around the coseismic rupture. Areas sliding aseismically just after the mainshock are thus limited in size around the coseismic rupture, suggesting that frictional properties vary at a small scale around the rupture zone. It may also suggest that the regions adjacent to coseismic rupture are potentially unstable (i.e., are steady-state velocity weakening). This interpretation agrees with the results of Gualandi et al. (2014) suggesting the longer-term afterslip regions that are also located farther away from the coseismic ruptured zone are characterized by a transition between velocity-weakening and velocity-strengthening behavior. This implies that coseismic rupture occurs and triggers early afterslip in velocity weakening regions, while afterslip propagates away from the ruptured zone in fault regions that progressively become stable with the distance to the mainshock.

In Figure 10, we compare the slip distributions imaged for the mainshock and 6 days after, with the distribution of aftershocks detected over 6 days and 9 months after the mainshock (Valoroso et al., 2013). As for many earthquakes, aftershocks are distributed mainly at the ends of the fault (Das \& Henry, 2003) with few events located near the coseismic rupture. Six days after the mainshock (Figure 10a), our results show no clear correlation between the location of early afterslip and aftershocks. Months after the mainshock, the areas with a high density of aftershocks are similar to 6 days after the mainshock (as suggested by Henry \& Das, 2001, whereas the cumulated number of aftershocks is 8 times larger; see Figure S17), and the postseismic slip has extended farther away from the coseismic rupture. This is why we can observe a spatial correlation between some areas of long-term postseismic slip and aftershocks (Cheloni et al., 2014; D'Agostino et al., 2012). The spatial correlation is particularly striking for the southern afterslip patch, for which few early aftershocks are located within the early afterslip area (Figure 10a) while the aftershock cluster overlies the monthly afterslip that propagated outward from the coseismically ruptured zone (Figure 10b).

From this analysis, we can thus draw only one conclusion: There is no correlation between the area of large $(>15 \mathrm{~cm})$ early afterslip and the location of aftershocks for the first few days after the mainshock. This 
conclusion contradicts the observations made for some other earthquakes although mainly at longer time scales (e.g., Hsu et al., 2006; Perfettini \& Avouac, 2007; Ross et al., 2017; Wang et al., 2012for time periods spanning respectively 11 months, 3.5 years, 5 days, and 2.5 months). Our results could also suggest that, for some parts of the fault, aftershocks nucleation precedes aseismic slip which is going to occur for months after the mainshock; aftershocks could thus be partly explained by stress changes due to the coseismic rupture. But these aftershocks could also be triggered by early afterslip with an amplitude so low that it is not inferred by our model. The absence of clear correlation between early afterslip and aftershocks may also be related to the presence of high-pressure fluids in the seismogenic zone of the L'Aquila event, and of Central Italy in general, with the widespread emissions of $\mathrm{CO}_{2}$ rich fluids for deep origin (Chiodini et al., 2000, 2011; Frezzotti et al., 2009). Already, Miller et al. (2004) and Antonioli et al. (2005) proposed that the aftershocks and spatiotemporal migration of the seismicity of the 1997 Umbria-Marche seismic sequence ( $80 \mathrm{~km}$ NE of the L'Aquila event) were driven by the coseismically induced fluid pressure migration. Similarly, the increase in seismicity rate of the L'Aquila earthquake and the occurrence of some aftershocks may have been driven by fluid flows (Luccio et al., 2010; Malagnini et al., 2012; Terakawa et al., 2010), as for the aftershock migration following the 2016 Amatrice earthquake (Tung \& Masterlark, 2018; Walters et al., 2018). High-pressure fluids have been observed before the coseismic rupture and may have impacted the nucleation phase of the L'Aquila earthquake (Lucente et al., 2010). Finally, Malagnini et al. (2012) show that the strength of the Campotosto fault, just north of the main rupture (see Figure 2), has been controlled by fluid migration for at least 6 days after the mainshock, a time window corresponding to our study of early afterslip. The perturbations in pore fluid pressure induced by the coseismic rupture may have triggered the first aftershocks of the L'Aquila earthquake. Fluid migration may have prevented aftershocks and early afterslip from affecting the same areas of the fault, especially if the increase in fluid pressure first produced aseismic slip, followed by triggered seismicity around the pore pressure front (Miller et al., 2004). Finally, if early aftershocks were triggered by changes in fluid pressure, it may justify the possibility that some of these early aftershocks nucleated before the occurrence of long-term afterslip in similar regions of the fault.

\section{Conclusion}

In this study, we use a simple and efficient approach to account for the differences in temporal resolution of various geodetic data sets. A redesign of the Green's functions matrix allows us to optimize the use of the information content of data sets covering different time periods. In particular, we propose here generic equations governing the CTW approach and detail the benefits of this approach with toy models. A comparable strategy has already been proposed by Floyd et al. (2016) and used in an optimization framework. With the CTW approach, we image simultaneously the strictly coseismic slip and the early afterslip (6 days after the mainshock) of the $2009 M_{w} 6.3$ L'Aquila earthquake using two data sets: One covers the two slip episodes (e.g., InSAR), while the other records the coseismic signal only (e.g., continuous GNSS). We show that when the two phases are inverted independently, as is usually the case, the estimated slip distributions are not reliable because strictly coseismic observations are usually of poor spatial resolution. Additionally, overlooking the early postseismic deformation results in models that overestimate the coseismic slip and underestimate the total postseismic slip budget. In contrast, the CTW approach allows us to accurately estimate both coseismic and early postseismic slip models. More generally, the CTW approach will also be useful to discriminate geodetic signals from earthquakes that cluster closely in space and time, or from different phases of the postseismic deformation.

Our results show that neglecting the contribution of the early postseismic deformation will likely bias estimates of the coseismic and/or the postseismic slip. For our test case of the L'Aquila earthquake, the peak coseismic slip is likely $30 \%$ greater when early postseismic signal is recorded as coseismic deformation. The long-term afterslip estimates are underestimated by a factor of 3 when the first 6 days of postseismic deformation are not acknowledged. Our investigation of the L'Aquila event also stressed the strong influence of uncertainties in the forward model, mainly stemming from our imperfect knowledge of the fault geometry and the Earth structure, on the imaged slip distributions. These uncertainties alone are sufficient to cause contradictory interpretations on the slip history on the fault (e.g., with the existence of shallow or dip slip).

Our preferred slip model for the L'Aquila earthquake tends to be simpler than many previous models, with one thin horizontal band of slip located around 7-km depth, reaching $150 \mathrm{~cm}$ in amplitude near its southern 
end. Our model thus excludes the possibility of major shallow or deep coseismic slip patches (less than a few kilometers or deeper than 10). The early postseismic slip (6 days after the mainshock) mostly occur in the same intermediate depth range $(7 \pm 3 \mathrm{~km})$, initiating on the edges of the coseismic slip, with possibly some overlap. Some afterslip may also have occurred at greater depths. A comparison with longer-term afterslip models suggests that the early afterslip patches might have simply expanded over time from their initial position. Aftershocks are more spatially distributed $(7 \pm 5 \mathrm{~km})$ but still concentrated at intermediate depth. Several studies suggest that aftershocks might be driven by afterslip (e.g., Hsu et al., 2006; Perfettini \& Avouac, 2007; Perfettini et al., 2018; Ross et al., 2017; Sladen et al., 2010) but here aftershocks are only partially overlapping. This result suggests that postseismic reloading may be influenced by fluids as advocated in several previous studies (e.g., Guglielmi et al., 2015; Luccio et al., 2010; Malagnini et al., 2012; Terakawa et al., 2010; Scuderi \& Collettini, 2016).

\section{Acknowledgments}

We thank Richard Walters for his thorough and constructive review. We thank Frederic Cappa for helpful discussions. We are extremely grateful to Frederica Magnoni who shared her 3-D crustal model for the L'Aquila area (Magnoni et al., 2014), to Luisa Valoroso who provided the aftershock catalog for the L'Aquila earthquake (Valoroso et al., 2013), and to Simone Atzori for sharing the InSAR data (Atzori et al., 2009). The Bayesian simulations were performed on the HPC-Regional Center ROMEO (https:// romeo.univ-reims.fr) of the University of Reims Champagne-Ardenne (France). The Classic Slip Inversion (CSI) Python library created by Romain Jolivet was used to build inputs for the Bayesian algorithm. Discussed slip models of Gualandi et al. (2014), Gallovic et al. (2015), and Cirella et al. (2012) have been retrieved from SRCMOD (http://equake-rc.info/ SRCMOD/, Mai \& Thingbaijam, 2014) Figures were generated with the Matplotlib and Seaborn Python libraries and with the Generic Mapping Tools library. This study was supported by the French National Research Agency (ANR) JCJC E-POST (ANR-14-CE03002-01JCJC 'E-POST'). Théa Ragon was supported by a fellowship from the French Ministry of Research and Higher Education

\section{References}

Albano, M., Barba, S., Saroli, M., Moro, M., Malvarosa, F., Costantini, M., et al. (2015). Gravity-driven postseismic deformation following the $M_{w} 6.32009$ L'Aquila (Italy) earthquake. Scientific Reports, 5, 16558. https://doi.org/10.1038/srep16558

Antonioli, A., Piccinini, D., Chiaraluce, L., \& Cocco, M. (2005). Fluid flow and seismicity pattern: Evidence from the 1997 Umbria-Marche (central Italy) seismic sequence. Geophysical Research Letters, 32, L10311. https://doi.org/10.1029/2004GL022256

Anzidei, M., Boschi, E., Cannelli, V., Devoti, R., Esposito, A., Galvani, A., et al. (2009). Coseismic deformation of the destructive April 6 , 2009 L'Aquila earthquake (central Italy) from GPS data. Geophysical Research Letters, 36, L17307. https://doi.org/10.1029/ 2009GL039145

Aster, R. C., Borchers, B., \& Thurber, C. H. (2005). Parameter estimation and inverse problems, no. 90 in International Geophysics Series. New York, NY: Academic Press.

Atzori, S., Hunstad, I., Chini, M., Salvi, S., Tolomei, C., Bignami, C., et al. (2009). Finite fault inversion of DInSAR coseismic displacement of the 2009 L'Aquila earthquake (central Italy). Geophysical Research Letters, 36, L15305. https://doi.org/10.1029/2009GL039293

Avallone, A., Marzario, M., Cirella, A., Piatanesi, A., Rovelli, A., Di Alessandro, C., et al.(2011). Very high rate (10 Hz) GPS seismology for moderate-magnitude earthquakes: The case of the $M_{w} 6.3$ L'Aquila (central Italy) event. Journal of Geophysical Research, $116, \mathrm{~B} 02305$. https://doi.org/10.1029/2010JB007834

Balestra, J., \& Delouis, B. (2015). Reassessing the rupture process of the 2009 L'Aquila earthquake $\left(M_{w} 6.3\right)$ on the Paganica Fault and investigating the possibility of coseismic motion on secondary faults. Bulletin of the Seismological Society of America, 105(3), 1517-1539. https://doi.org/10.1785/0120140239

Barbot, S., \& Fialko, Y. (2010). A unified continuum representation of post-seismic relaxation mechanisms: Semi-analytic models of afterslip, poroelastic rebound and viscoelastic flow. Geophysical Journal International, 182(3), 1124-1140. https://doi.org/10.1111/j.1365246X.2010.04678.x

Barnhart, W. D., Brengman, C. M. J., Li, S., \& Peterson, K. E. (2018). Ramp-flat basement structures of the Zagros Mountains inferred from co-seismic slip and afterslip of the $2017 M_{w} 7.3$ Darbandikhan, Iran/Iraq earthquake. Earth and Planetary Science Letters, $496,96-107$. https://doi.org/10.1016/j.epsl.2018.05.036

Beresnev, I. A. (2003). Uncertainties in finite-fault slip inversions: To what extent to believe? (A critical review). Bulletin of the Seismological Society of America, 93(6), 2445-2458. https://doi.org/10.1785/0120020225

Bletery, Q., Sladen, A., Jiang, J., \& Simons, M. (2016). A Bayesian source model for the 2004 great Sumatra-Andaman earthquake. Journal of Geophysical Research: Solid Earth, 121, 5116-5135. https://doi.org/10.1002/2016JB012911

Boncio, P., Lavecchia, G., Milana, G., \& Rozzi, B. (2004a). Seismogenesis in Central Apennines, Italy: An integrated analysis of minor earthquake sequences and structural data in the Amatrice-Campotosto area. Annals of Geophysics, 47(6), 1723-1742.

Boncio, P., Lavecchia, G., \& Pace, B. (2004b). Defining a model of 3D seismogenic sources for Seismic Hazard Assessment applications: The case of central Apennines (Italy). Journal of Seismology, 8(3), 407-425. https://doi.org/10.1023/B:JOSE.0000038449.78801.05

Boncio, P., Pizzi, A., Brozzetti, F., Pomposo, G., Lavecchia, G., Di Naccio, D., \& Ferrarini, F. (2010). Coseismic ground deformation of the 6 April 2009 L'Aquila earthquake (central Italy, $M_{w} 6.3$ ). Geophysical Research Letters, 37, L06308. https://doi.org/10.1029/ 2010GL042807

Burgmann, R., Segall, P., Lisowski, M., \& Svarc, J. (1997). Postseismic strain following the 1989 Loma Prieta earthquake from GPS and leveling measurements. Journal of Geophysical Research, 102(B3), 4933-4955. https://doi.org/10.1029/96JB03171

Causse, M., Cotton, F., \& Mai, P. M. (2010). Constraining the roughness degree of slip heterogeneity. Journal of Geophysical Research, 115 , B05304. https://doi.org/10.1029/2009JB006747

Chan, C.-H., \& Stein, R. S. (2009). Stress evolution following the 1999 Chi-Chi, Taiwan, earthquake: Consequences for afterslip, relaxation, aftershocks and departures from Omori decay. Geophysical Journal International, 177(1), 179-192. https://doi.org/10.1111/j.1365246X.2008.04069.X

Cheloni, D., D'Agostino, N., D'Anastasio, E., Avallone, A., Mantenuto, S., Giuliani, R., et al. (2010). Coseismic and initial post-seismic slip of the $2009 M_{w} 6.3$ L'Aquila earthquake, Italy, from GPS measurements. Geophysical Journal International, 181(3), 1539-1546. https://doi. org/10.1111/j.1365-246X.2010.04584.x

Cheloni, D., Giuliani, R., D'Anastasio, E., Atzori, S., Walters, R. J., Bonci, L., et al. (2014). Coseismic and post-seismic slip of the 2009 L'Aquila (central Italy) MW 6.3 earthquake and implications for seismic potential along the Campotosto fault from joint inversion of high-precision levelling, InSAR and GPS data. Tectonophysics, 622, 168-185. https://doi.org/10.1016/j.tecto.2014.03.009

Chiarabba, C., Amato, A., Anselmi, M., Baccheschi, P., Bianchi, I., Cattaneo, M., et al. (2009). The 2009 L'Aquila (central Italy) MW6.3 earthquake: Main shock and aftershocks. Geophysical Research Letters, 36, L18308. https://doi.org/10.1029/2009GL039627

Chiaraluce, L. (2012). Unravelling the complexity of Apenninic extensional fault systems: A review of the 2009 L'Aquila earthquake (Central Apennines, Italy). Journal of Structural Geology, 42, 2-18. https://doi.org/10.1016/j.jsg.2012.06.007

Chiaraluce, L., Valoroso, L., Piccinini, D., Di Stefano, R., \& De Gori, P. (2011). The anatomy of the 2009 L'Aquila normal fault system (central Italy) imaged by high resolution foreshock and aftershock locations. Journal of Geophysical Research, 116, B12311. https://doi. org/10.1029/2011JB008352 
Chiodini, G., Caliro, S., Cardellini, C., Frondini, F., Inguaggiato, S., \& Matteucci, F. (2011). Geochemical evidence for and characterization of $\mathrm{CO}_{2}$ rich gas sources in the epicentral area of the Abruzzo 2009 earthquakes. Earth and Planetary Science Letters, 304(3), 389-398. https://doi.org/10.1016/j.epsl.2011.02.016

Chiodini, G., Frondini, F., Cardellini, C., Parello, F., \& Peruzzi, L. (2000). Rate of diffuse carbon dioxide Earth degassing estimated from carbon balance of regional aquifers: The case of central Apennine, Italy. Journal of Geophysical Research, 105(B4), 8423-8434. https://doi. org/10.1029/1999JB900355

Chlieh, M., Avouac, J.-P., Hjorleifsdottir, V., Song, T.-R. A., Ji, C., Sieh, K., et al. (2007). Coseismic slip and afterslip of the great $M_{w} 9.15$ Sumatra-Andaman earthquake of 2004. Bulletin of the Seismological Society of America, 97(1A), S152-S173. https://doi.org/10.1785/ 0120050631

Cirella, A., Piatanesi, A., Tinti, E., Chini, M., \& Cocco, M. (2012). Complexity of the rupture process during the 2009 L'Aquila, Italy, earthquake. Geophysical Journal International, 190(1), 607-621. https://doi.org/10.1111/j.1365-246X.2012.05505.x

Cubas, N., Lapusta, N., Avouac, J.-P., \& Perfettini, H. (2015). Numerical modeling of long-term earthquake sequences on the NE Japan megathrust: Comparison with observations and implications for fault friction. Earth and Planetary Science Letters, 419(Supplement C), 187-198. https://doi.org/10.1016/j.epsl.2015.03.002

D'Agostino, N., Cheloni, D., Fornaro, G., Giuliani, R., \& Reale, D. (2012). Space-time distribution of afterslip following the 2009 L'Aquila earthquake. Journal of Geophysical Research, 117, B02402. https://doi.org/10.1029/2011JB008523

Das, S., \& Henry, C. (2003). Spatial relation between main earthquake slip and its aftershock distribution. Reviews of Geophysics, $41(3), 1013$. https://doi.org/10.1029/2002RG000119

Delouis, B., Giardini, D., Lundgren, P., \& Salichon, J. (2002). Joint inversion of InSAR, GPS, teleseismic, and strong-motion data for the spatial and temporal distribution of earthquake slip: Application to the 1999 Izmit mainshock. Bulletin of the Seismological Society of America, 92(1), 278-299. https://doi.org/10.1785/0120000806

Dieterich, J. (1994). A constitutive law for rate of earthquake production and its application to earthquake clustering. Journal of Geophysical Research, 99(B2), 2601-2618. https://doi.org/10.1029/93JB02581

Du, Y., Aydin, A., \& Segall, P. (1992). Comparison of various inversion techniques as applied to the determination of a geophysical deformation model for the 1983 Borah Peak earthquake. Bulletin of the Seismological Society of America, 82(4), 1840-1866.

Duputel, Z., Agram, P. S., Simons, M., Minson, S. E., \& Beck, J. L. (2014). Accounting for prediction uncertainty when inferring subsurface fault slip. Geophysical journal international, 197(1), 464-482.

EMERGEO Working Group (2010). Evidence for surface rupture associated with the $M_{w} 6.3$ L'Aquila earthquake sequence of April 2009 (central Italy). Terra Nova, 22(1), 43-51. https://doi.org/10.1111/j.1365-3121.2009.00915.x

Elliott, J. R., Copley, A. C., Holley, R., Scharer, K., \& Parsons, B. (2013). The $2011 M_{w} 7.1$ Van (eastern Turkey) earthquake. Journal of Geophysical Research: Solid Earth, 118, 1619-1637. https://doi.org/10.1002/jgrb.50117

Falcucci, E., Gori, S., Peronace, E., Fubelli, G., Moro, M., Saroli, M., et al. (2009). The Paganica fault and surface coseismic ruptures caused by the 6 April 2009 earthquake (L'Aquila, central Italy). Seismological Research Letters, 80(6), 940-950. https://doi.org/10.1785/ gssrl.80.6.940

Floyd, M. A., Walters, R. J., Elliott, J. R., Funning, G. J., Svarc, J. L., Murray, J. R., et al. (2016). Spatial variations in fault friction related to lithology from rupture and afterslip of the 2014 South Napa, California, earthquake. Geophysical Research Letters, 43, 6808-6816. https:// doi.org/10.1002/2016GL069428

Freed, A. M. (2007). Afterslip (and only afterslip) following the 2004 Parkfield, California, earthquake. Geophysical Research Letters, 34, L06312. https://doi.org/10.1029/2006GL029155

Freed, A. M., \& Burgmann, R. (2004). Evidence of power-law flow in the Mojave desert mantle. Nature, 430(6999), 548-51.

Frezzotti, M. L., Peccerillo, A., \& Panza, G. (2009). Carbonate metasomatism and $\mathrm{CO}_{2}$ lithosphere-asthenosphere degassing beneath the Western Mediterranean: An integrated model arising from petrological and geophysical data. Chemical Geology, 262(1), 108-120. https:// doi.org/10.1016/j.chemgeo.2009.02.015

Gallovic, F., Imperatori, W., \& Mai, P. M. (2015). Effects of three-dimensional crustal structure and smoothing constraint on earthquake slip inversions: Case study of the $M_{w} 6.32009$ L'Aquila earthquake. Journal of Geophysical Research: Solid Earth, 120, 428-449. https://doi. org/10.1002/2014JB011650

Gombert, B., Duputel, Z., Jolivet, R., Doubre, C., Rivera, L., \& Simons, M. (2017). Revisiting the 1992 Landers earthquake: A Bayesian exploration of co-seismic slip and off-fault damage. Geophysical Journal International, 212, 839-852. https://doi.org/10.1093/gji/ggx455

Gualandi, A., Avouac, J.-P., Galetzka, J., Genrich, J. F., Blewitt, G., Adhikari, L. B., et al. (2017). Pre- and post-seismic deformation related to the 2015, $M_{w} 7.8$ Gorkha earthquake, Nepal. Tectonophysics, 714, 90-106. https://doi.org/10.1016/j.tecto.2016.06.014

Gualandi, A., Serpelloni, E., \& Belardinelli, M. E. (2014). Space-time evolution of crustal deformation related to the $M_{w} 6.3$, 2009 L'Aquila earthquake (central Italy) from principal component analysis inversion of GPS position time-series. Geophysical Journal International, 197, 174-191. https://doi.org/10.1093/gii/ggt522

Guglielmi, Y., Cappa, F., Avouac, J.-P., Henry, P., \& Elsworth, D. (2015). Seismicity triggered by fluid injection-induced aseismic slip. Science, 348(6240), 1224-1226. https://doi.org/10.1126/science.aab0476

He, P., Hetland, E. A., Wang, Q., Ding, K., Wen, Y., \& Zou, R. (2017). Coseismic slip in the $2016 M_{w} 7.8$ Ecuador earthquake imaged from Sentinel-1a radar interferometry. Seismological Research Letters, 88(2A), 277-286. https://doi.org/10.1785/0220160151

Helmstetter, A., \& Shaw, B. E. (2009). Afterslip and aftershocks in the rate-and-state friction law. Journal of Geophysical Research, 114, B01308. https://doi.org/10.1029/2007JB005077

Henry, C., \& Das, S. (2001). Aftershock zones of large shallow earthquakes: Fault dimensions, aftershock area expansion and scaling relations. Geophysical Journal International, 147(2), 272-293. https://doi.org/10.1046/j.1365-246X.2001.00522.x

Herrmann, R. B., Malagnini, L., \& Munafo, I. (2011). Regional moment tensors of the 2009 L'Aquila earthquake sequence. Bulletin of the Seismological Society of America, 101(3), 975-993. https://doi.org/10.1785/0120100184

Hsu, Y.-J., Simons, M., Avouac, J.-P., Galetzka, J., Sieh, K., Chlieh, M., et al. (2006). Frictional afterslip following the 2005 Nias-Simeulue earthquake, Sumatra. Science, 312(5782), 1921-1926. https://doi.org/10.1126/science.1126960

Johnson, K. M., Fukuda, J., \& Segall, P. (2012). Challenging the rate-state asperity model: Afterslip following the 2011 M9 Tohoku-oki, Japan, earthquake. Geophysical Research Letters, 39, L20302. https://doi.org/10.1029/2012GL052901

Jolivet, R., Lasserre, C., Doin, M.-P., Guillaso, S., Peltzer, G., Dailu, R., et al. (2012). Shallow creep on the Haiyuan Fault (Gansu, China) revealed by SAR interferometry. Journal of Geophysical Research, 117, B06401. https://doi.org/10.1029/2011JB008732

Jonsson, S., Segall, P., Pedersen, R., \& Bjornsson, G. (2003). Post-earthquake ground movements correlated to pore-pressure transients. Nature, 424(6945), 179-83. 
Kato, A., Obara, K., Igarashi, T., Tsuruoka, H., Nakagawa, S., \& Hirata, N. (2012). Propagation of slow slip leading up to the $2011 M_{w} 9.0$ Tohoku-Oki earthquake. Science, 335(6069), 705-708. https://doi.org/10.1126/science.1215141

Lavecchia, G., Ferrarini, F., Brozzetti, F., Nardis, R. D., Boncio, P., \& Chiaraluce, L. (2012). From surface geology to aftershock analysis: Constraints on the geometry of the L'Aquila 2009 seismogenic fault system. Italian Journal of Geosciences, 131(3), 330-347. https://doi. org/10.3301/IJG.2012.24

Lin, Y.-n. N., Sladen, A., Ortega-Culaciati, F., Simons, M., Avouac, J.-P., Fielding, E. J., et al. (2013). Coseismic and postseismic slip associated with the 2010 Maule earthquake, Chile: Characterizing the Arauco Peninsula barrier effect. Journal of Geophysical Research: Solid Earth, 118, 3142-3159. https://doi.org/10.1002/jgrb.50207

Lohman, R. B., \& Simons, M. (2005). Some thoughts on the use of InSAR data to constrain models of surface deformation: Noise structure and data downsampling. Geochemistry, Geophysics, Geosystems, 6, Q01007. https://doi.org/10.1029/2004GC000841

Luccio, F. D., Ventura, G., Giovambattista, R. D., Piscini, A., \& Cinti, F. R. (2010). Normal faults and thrusts reactivated by deep fluids: The 6 April $2009 M_{w} 6.3$ L'Aquila earthquake, central Italy. Journal of Geophysical Research, 115, B06315. https://doi.org/10.1029/ 2009JB007190

Lucente, F. P., Gori, P. D., Margheriti, L., Piccinini, D., Bona, M. D., Chiarabba, C., \& Agostinetti, N. P. (2010). Temporal variation of seismic velocity and anisotropy before the 2009 MW 6.3 L'Aquila earthquake, Italy. Geology, 38(11), 1015-1018. https://doi.org/10.1130/G31463.1

Magnoni, F., Casarotti, E., Michelini, A., Piersanti, A., Komatitsch, D., Peter, D., \& Tromp, J. (2014). Spectral element simulations of seismic waves generated by the 2009 L'Aquila earthquake. Bulletin of the Seismological Society of America, 104(1), 73-94. https://doi.org/10.1785/ 0120130106

Mai, P. M., \& Thingbaijam, K. K. S. (2014). SRCMOD: An online database of finite-fault rupture models. Seismological Research Letters, 85(6), 1348-1357. https://doi.org/10.1785/0220140077

Malagnini, L., Lucente, F. P., Gori, P. D., Akinci, A., \& Munafo', I. (2012). Control of pore fluid pressure diffusion on fault failure mode: Insights from the 2009 L'Aquila seismic sequence. Journal of Geophysical Research, 117, B05302. https://doi.org/10.1029/2011JB008911

Malservisi, R., Schwartz, S. Y., Voss, N., Protti, M., Gonzalez, V., Dixon, T. H., et al. (2015). Multiscale postseismic behavior on a megathrust: The 2012 Nicoya earthquake, Costa Rica. Geochemistry, Geophysics, Geosystems, 16, 1848-1864. https://doi.org/10.1002/2015GC005794

Marone, C. J., Scholtz, C. H., \& Bilham, R. (1991). On the mechanics of earthquake afterslip. Journal of Geophysical Research, 96(B5), 8441-8452. https://doi.org/10.1029/91JB00275

Miller, S. A., Collettini, C., Chiaraluce, L., Cocco, M., Barchi, M., \& Kaus, B. J. P. (2004). Aftershocks driven by a high-pressure CO ${ }_{2}$ source at depth. Nature, 427(6976), 724-727. https://doi.org/10.1038/nature02251

Minson, S. E., Simons, M., \& Beck, J. L. (2013). Bayesian inversion for finite fault earthquake source models I: Theory and algorithm. Geophysical Journal International, 194(3), 1701-1726. https://doi.org/10.1093/gji/ggt180

Miyazaki, S., Segall, P., Fukuda, J., \& Kato, T. (2004). Space time distribution of afterslip following the 2003 Tokachi-oki earthquake: Implications for variations in fault zone frictional properties. Geophysical Research Letters, 31, L06623. https://doi.org/10.1029/ 2003GL019410

Munekane, H. (2012). Coseismic and early postseismic slips associated with the 2011 off the Pacific coast of Tohoku earthquake sequence: EOF analysis of GPS kinematic time series. Earth, Planets and Space, 64(12), 3. https://doi.org/10.5047/eps.2012.07.009

Nur, A., \& Mavko, G. (1974). Postseismic viscoelastic rebound. Science, 183(4121), 204-206. https://doi.org/10.1126/science.183.4121.204

Parzen, E. (1962). On estimation of a probability density function and mode. The Annals of Mathematical Statistics, 33(3), 1065-1076.

Peltzer, G., Rosen, P., Rogez, F., \& Hudnut, K. (1998). Poroelastic rebound along the Landers 1992 earthquake surface rupture. Journal of Geophysical Research, 103(B12), 30,131-30,145. https://doi.org/10.1029/98JB02302

Peng, Z., \& Zhao, P. (2009). Migration of early aftershocks following the 2004 Parkfield earthquake. Nature Geoscience, 2, 877-881. https:// doi.org/10.1038/ngeo697

Perfettini, H., \& Avouac, J.-P. (2004). Postseismic relaxation driven by brittle creep: A possible mechanism to reconcile geodetic measurements and the decay rate of aftershocks, application to the Chi-Chi earthquake, Taiwan. Journal of Geophysical Research, 109, B02304. https://doi.org/10.1029/2003JB002488

Perfettini, H., \& Avouac, J.-P. (2007). Modeling afterslip and aftershocks following the 1992 Landers earthquake. Journal of Geophysical Research, 112, B07409. https://doi.org/10.1029/2006JB004399

Perfettini, H., \& Avouac, J. P. (2014). The seismic cycle in the area of the $2011 M_{w} 9.0$ Tohoku-Oki earthquake. Journal of Geophysical Research: Solid Earth, 119, 4469-4515. https://doi.org/10.1002/2013JB010697

Perfettini, H., Frank, W. B., Marsan, D., \& Bouchon, M. (2018). A model of aftershock migration driven by afterslip. Geophysical Research Letters, 45, 2283-2293. https://doi.org/10.1002/2017GL076287

Pollitz, F. F., Burgmann, R., \& Segall, P. (1998). Joint estimation of afterslip rate and postseismic relaxation following the 1989 Loma Prieta earthquake. Journal of Geophysical Research, 103(B11), 26975-26992. https://doi.org/10.1029/98JB01554

Pondrelli, S., Salimbeni, S., Morelli, A., Ekstrom, G., Olivieri, M., \& Boschi, E. (2010). Seismic moment tensors of the April 2009, L'Aquila (Central Italy), earthquake sequence. Geophysical Journal International, 180(1), 238-242. https://doi.org/10.1111/j.1365246X.2009.04418.X

Ragon, T., Sladen, A., \& Simons, M. (2018). Accounting for uncertain fault geometry in earthquake source inversions-I: Theory and simplified application. Geophysical Journal International, 214(2), 1174-1190. https://doi.org/10.1093/gji/ggy187

Ragon, T., Sladen, A., \& Simons, M. (2019). Accounting for uncertain fault geometry in earthquake source inversions-II: Application to the $M_{w} 6.2$ Amatrice earthquake, Central Italy. Geophysical Journal International, 217, 689-707. https://doi.org/10.1093/gji/ggz180

Rice, J., \& Ruina, A. L. (1983). Stability of steady frictional slipping. Journal of Applied Mechanics, 50, 343. https://doi.org/10.1115/ 1.3167042

Rosen, P. A., Henley, S., Peltzer, G., \& Simons, M. (2004). Update repeat orbit interferometry package released. EOS Transactions, 85, 47-47. https://doi.org/10.1029/2004EO050004

Ross, Z. E., Rollins, C., Cochran, E. S., Hauksson, E., Avouac, J.-P., \& Ben-Zion, Y. (2017). Aftershocks driven by afterslip and fluid pressure sweeping through a fault-fracture mesh. Geophysical Research Letters, 44, 8260-8267. https://doi.org/10.1002/2017GL074634

Ruiz, S., Metois, M., Fuenzalida, A., Ruiz, J., Leyton, F., Grandin, R., et al. (2014). Intense foreshocks and a slow slip event preceded the 2014 Iquique $M_{w} 8.1$ earthquake. Science, 345(6201), 1165-1169. https://doi.org/10.1126/science.1256074

Salman, R., Hill, E. M., Feng, L., Lindsey, E. O., Mele Veedu, D., Barbot, S., et al. (2017). Piecemeal rupture of the Mentawai Patch, Sumatra: The $2008 M_{w} 7.2$ North Pagai earthquake sequence. Journal of Geophysical Research: Solid Earth, 122, 9404-9419. https://doi.org/ 10.1002/2017JB014341

Scognamiglio, L., Tinti, E., \& Michelini, A. (2009). Real-time determination of seismic moment tensor for the Italian region. Bulletin of the Seismological Society of America, 99(4), 2223-2242. https://doi.org/10.1785/0120080104 
Scuderi, M. M., \& Collettini, C. (2016). The role of fluid pressure in induced vs. triggered seismicity: Insights from rock deformation experiments on carbonates. Scientific Reports, 6(24), 852. https://doi.org/10.1038/srep24852

Segall, P. (2010). Earthquake and volcano deformation. Princeton: Princeton University Press. google-Books-ID: x6Fp4hMBTpYC

Serpelloni, E., Anderlini, L., \& Belardinelli, M. E. (2012). Fault geometry, coseismic-slip distribution and Coulomb stress change associated with the 2009 April 6, $M_{w}$ 6.3, L'Aquila earthquake from inversion of GPS displacements. Geophysical Journal International, 188(2), 473-489. https://doi.org/10.1111/j.1365-246X.2011.05279.x

Sladen, A., Tavera, H., Simons, M., Avouac, J. P., Konca, A. O., Perfettini, H., et al. (2010). Source model of the $2007 M_{w} 8.0$ Pisco, Peru earthquake: Implications for seismogenic behavior of subduction megathrusts. Journal of Geophysical Research, 115, B02405. https://doi. org/10.1029/2009JB006429

Smith, B., \& Sandwell, D. (2004). A three-dimensional semianalytic viscoelastic model for time-dependent analyses of the earthquake cycle. Journal of Geophysical Research, 109, B12401. https://doi.org/10.1029/2004JB003185

Terakawa, T., Zoporowski, A., Galvan, B., \& Miller, S. A. (2010). High-pressure fluid at hypocentral depths in the L'Aquila region inferred from earthquake focal mechanisms. Geology, 38(11), 995-998. https://doi.org/10.1130/G31457.1

Trasatti, E., Kyriakopoulos, C., \& Chini, M. (2011). Finite element inversion of DInSAR data from the $M_{w} 6.3$ L'Aquila earthquake, 2009 (Italy). Geophysical Research Letters, 38, L08306. https://doi.org/10.1029/2011GL046714

Tung, S., \& Masterlark, T. (2018). Resolving source geometry of the 24 August 2016 Amatrice, Central Italy, earthquake from InSAR data and 3D finite-element modeling. Bulletin of the Seismological Society of America, 108(2), 553-572. https://doi.org/10.1785/0120170139

Twardzik, C., Vergnolle, M., Sladen, A., \& Avallone, A. (2019). Unravelling the contribution of early postseismic deformation using subdaily GNSS positioning I. Scientific Reports, 9(1), 1775. https://doi.org/10.1038/s41598-019-39038-z

Valoroso, L., Chiaraluce, L., Piccinini, D., Di Stefano, R., Schaff, D., \& Waldhauser, F. (2013). Radiography of a normal fault system by 64,000 high-precision earthquake locations: The 2009 L'Aquila (central Italy) case study. Journal of Geophysical Research: Solid Earth, 118, 1156-1176. https://doi.org/10.1002/jgrb.50130

Vittori, E., Manna, P. D., Blumetti, A. M., Comerci, V., Guerrieri, L., Esposito, E., et al. (2011). Surface faulting of the 6 April $2009 M_{w} 6.3$ L'Aquila earthquake in central Italy. Bulletin of the Seismological Society of America, 101(4), 1507-1530. https://doi.org/10.1785/ 0120100140

Volpe, M., Atzori, S., Piersanti, A., \& Melini, D. (2015). The 2009 L'Aquila earthquake coseismic rupture: Open issues and new insights from 3D finite element inversion of GPS, InSAR and strong motion data. Annals of Geophysics, 58(2), S0221. https://doi.org/10.4401/ag-6711

Volpe, M., Piersanti, A., \& Melini, D. (2012). Complex 3-D finite element modelling of the 2009 April 6 L'Aquila earthquake by inverse analysis of static deformation. Geophysical Journal International, 188(3), 1339-1358. https://doi.org/10.1111/j.1365-246X.2011.05330.x

Walters, R. J., Gregory, L. C., Wedmore, L. N. J., Craig, T. J., McCaffrey, K., Wilkinson, M., et al.(2018). Dual control of fault intersections on stop-start rupture in the 2016 central Italy seismic sequence. Earth and Planetary Science Letters, 500, 1-14. https://doi.org/10.1016/j. epsl.2018.07.043

Wang, L., Hainzl, S., Zoller, G., \& Holschneider, M. (2012). Stress- and aftershock-constrained joint inversions for coseismic and postseismic slip applied to the 2004 M6.0 Parkfield earthquake. Journal of Geophysical Research, 117, B07406. https://doi.org/10.1029/2011JB009017

Yano, T. E., Shao, G., Liu, Q., Ji, C., \& Archuleta, R. J. (2014). Coseismic and potential early afterslip distribution of the $2009 M_{w} 6.3$ L'Aquila, Italy earthquake. Geophysical Journal International, 199(1), 23-40. https://doi.org/10.1093/gji/ggu241

Zhu, L., \& Rivera, L. A. (2002). A note on the dynamic and static displacements from a point source in multilayered media. Geophysical Journal International, 148(3), 619-627. https://doi.org/10.1046/j.1365-246X.2002.01610.x 